\title{
The Influence of a Submarine Canyon on the Circulation and Cross-Shore Exchanges around an Upwelling Front
}

\author{
GONZALO S. SALDÍAS \\ Department of Earth, Ocean and Atmospheric Sciences, University of British Columbia, Vancouver, British Columbia, Canada, \\ and Departamento de Física, Facultad de Ciencias, Universidad del Bío-Bío, Concepción, \\ and Centro FONDAP de Investigación en Dinámica de Ecosistemas Marinos de Altas Latitudes, Valdivia, Chile
}

SusAN E. AlLEN

Department of Earth, Ocean and Atmospheric Sciences, University of British Columbia, Vancouver, British Columbia, Canada

(Manuscript received 23 May 2019, in final form 17 March 2020)

\begin{abstract}
The response of a coastal ocean numerical model, typical of eastern boundaries, is investigated under upwelling-favorable wind forcing and with/without the presence of a submarine canyon. Experiments were run over three contrasting shelf depth/slope bathymetries and forced by an upwelling-favorable alongshore wind. Random noise in the wind stress field was used to trigger the onset of frontal instabilities, which formed around the upwelling front. Their development and evolution are enhanced over deeper (and less inclined) shelves. Experiments without a submarine canyon agree well with previous studies of upwelling frontal instabilities; baroclinic instabilities grow along the front in time. The addition of a submarine canyon incising the continental shelf dramatically changes the circulation and frontal characteristics. Intensified upwelling is channeled through the downstream side of the canyon in all depth/slope configurations. Farther downstream a downwelling area is generated, being larger and stronger on a shallow shelf. The canyon affects mainly the location of the southward upwelling jet, which is deflected inshore and accelerated after passing over the canyon. This process is accompanied by a break in the alongshore scale of the instabilities on either side of the canyon. Term balances of the depth-averaged cross-shore momentum equation reaffirm the downstream acceleration of the jet and the increased wavelength of the instabilities, and clarify the dominant balance between the advection and ageostrophic terms around the canyon.
\end{abstract}

\section{Introduction}

Dominant equatorward upwelling-favorable winds drive coastal upwelling along major eastern boundary systems during spring-summer (e.g., Nelson and Hutchings 1983; Allen et al. 1995; Letelier et al. 2009; Barton et al. 2013). This wind forcing promotes the offshore transport of water in the surface Ekman layer, with a compensating onshore flow at depth that brings cold, salty (and high density), nutrient-rich, and oxygen-poor water over the shelf (Brink 1983; Huyer 1983). The rise of these subsurface waters to the euphotic zone supports a large fraction of biological production and fisheries in these relatively small coastal areas (e.g., Carr and Kearns 2003). Upwelled waters over the shelf eventually reach

Corresponding author: Gonzalo S. Saldías, gsaldias@ubiobio.cl the surface forming a density front (upwelling front) separating relatively warm waters offshore from cold upwelling waters next to the coastal boundary (Brink 1983). The lateral density gradients around the front sustain the development and evolution of a geostrophically balanced upwelling jet that flows downstream with core velocities $\sim 0.5 \mathrm{~m} \mathrm{~s}^{-1}$ (e.g., O'Brien and Hurlburt 1972; Kosro et al. 1997; Castelao and Barth 2007). This process is also characterized by low (high) sea level nearshore (offshore) (e.g., Whitney and Allen 2009a), and the formation of prominent frontal instabilities in the form of filaments around the front (Flament et al. 1985; Washburn and Armi 1988; Barth 1989; Durski and Allen 2005; Troupin et al. 2012).

The presence of a submarine canyon breaks the continuity of the along-isobath geostrophic flow (Allen and Durrieu de Madron 2009), which leads to cross-isobath 
flow and exchange of water and tracers between the open ocean and the continental shelf (Hickey 1995; Alvarez et al. 1996; Skliris et al. 2001; Allen 2004; Allen and Hickey 2010; Ramos-Musalem and Allen 2019). As submarine canyons represent locations of increased ageostrophic circulation, their impacts on cross-shelf exchanges are potentially large at regional scales (Connolly and Hickey 2014; Brink 2016b). In general, several studies have analyzed the circulation within submarine canyons (e.g., Klinck 1996; Flexas et al. 2008; Allen and Hickey 2010), however, the influence of canyon-associated circulation on surrounding shelf waters has received less attention (e.g., Hickey 1998; Chen and Allen 1996).

Cross-shelf exchanges can be significantly enhanced not only by the presence of a major bathymetric barrier as a submarine canyon (Allen and Durrieu de Madron 2009), but also due to the high vorticity field created by frontal instabilities (Durski and Allen 2005; Wang and Jordi 2011). Although shelf-slope exchanges have been widely studied and reviewed (e.g., Houghton et al. 1988; Huthnance 1995; Dinniman and Klinck 2004; Brink 2016a), there is scarce information on the combined effect and/or the interaction between surface frontal instabilities and a submarine canyon. A few studies have considered the case of mesoscale instabilities over a submarine canyon under right bounded flow conditions (typical of downwelling alongshore currents; Jordi et al. 2005,2008 ), and thus, the effect of a submarine canyon over the circulation and characteristics of an upwelling front remains poorly understood. The aim of this study is to clarify this canyon effect and to quantify its impact on cross-shore exchanges for a typical eastern boundary upwelling system. Section 2 presents the details of the model configuration and experiments, section 3 contains the main results, the discussion is presented in section 4 , and finally the conclusions are highlighted in section 5 .

\section{Model configuration and experiments}

The Regional Ocean Modeling System (ROMS) is used in this study. ROMS is a primitive equation model formulated in finite-difference form with a sigmacoordinate representation in the vertical direction that solves the hydrostatic nonlinear primitive equations (Haidvogel et al. 2000; Shchepetkin and McWilliams 2005). Vertical differencing is achieved with terrainfollowing $s$ coordinates (Song and Haidvogel 1994). In this study, the model is run with a third-order upstream horizontal and a fourth-order centered vertical advection scheme for momentum and tracers. High-order advection is necessary to avoid spurious vertical velocities at the canyon rim due to stratified flow over steep topography using $s$ coordinates (Dawe and Allen 2010). The horizontal pressure gradient is treated with a spline density Jacobian (Shchepetkin and McWilliams 2003). Vertical mixing follows the Mellor-Yamada level 2.5 closure scheme (Mellor and Yamada 1982); the background vertical viscosity and diffusivity are $1 \times 10^{-5}$ and $5 \times 10^{-6} \mathrm{~m}^{2} \mathrm{~s}^{-1}$, respectively. Bottom stress is calculated with a quadratic drag law using a bottom roughness of $2 \times 10^{-2} \mathrm{~m}$. ROMS has been used in several studies of flow over topography, including submarine canyons (e.g., She and Klinck 2000; Dinniman and Klinck 2002; Rennie et al. 2009; Chen et al. 2014; Connolly and Hickey 2014) and banks (e.g., Kim et al. 2009; Whitney and Allen 2009a,b), and in studies of frontal instabilities (e.g., Durski and Allen 2005; Capet et al. 2008; Brink 2016a).

The model domain is a rectangular basin resembling the coastal ocean of an eastern boundary margin with 155 and $600 \mathrm{~km}$ in the cross-shore and alongshore direction, respectively (Fig. 1). Grid spacing increases beyond $x=-50 \mathrm{~km}$ in the cross-shore direction for computational efficiency from $0.5 \mathrm{~km}$ nearshore to $10 \mathrm{~km}$ at the offshore boundary, whereas a fixed $0.5 \mathrm{~km}$ of grid spacing is set in the alongshore direction and in the nearshore region $(x<50 \mathrm{~km})$ (Fig. 1b). Different shelf slope configurations are tested with all cases having a maximum depth of $500 \mathrm{~m}$ in the open ocean. We started with a basic configuration in order to compare with previous (and well recognized results) of upwelling over a canyon cutting across a deep flat shelf (Klinck 1996) — our basic experiments are run with the same shelf and canyon topography, which is defined by

$$
H(x, y)=H_{m}-\frac{H_{s}}{2}\left[1-\tanh \frac{-x-x_{o}(y)}{a}\right],
$$

where $H_{m}$ is the maximum depth of the domain $(500 \mathrm{~m})$, $H_{s}$ is the depth change from the continental shelf to the open ocean $(400 \mathrm{~m}), a$ is the transition scale defining the slope of the cross-shelf profile $(5 \mathrm{~km})$, and $x_{o}(y)$ is the location of the shelf break, defined as

$$
x_{o}(y)=x_{n}+x_{b}\left[1-\exp \frac{-\left(y^{2}-y_{o}^{2}\right)}{2 b^{2}}\right],
$$

where $x_{n}$ is the nominal distance of the head of the canyon from the coastal wall $(12 \mathrm{~km}), x_{b}$ is the distance added to $x_{n}$ to reach the shelf break $(10 \mathrm{~km}), y_{o}$ is the location of the center of the canyon (at $y=0 \mathrm{~km}$ ), and $b$ is the width scale of the canyon $(2.5 \mathrm{~km})$. This configuration produces a canyon $\sim 10 \mathrm{~km}$ wide in its mouth, $20 \mathrm{~km}$ long from its mouth to the head, and with sidewall steepness of $\sim 0.065$ (Figs. 2a,d). We also run a series of 

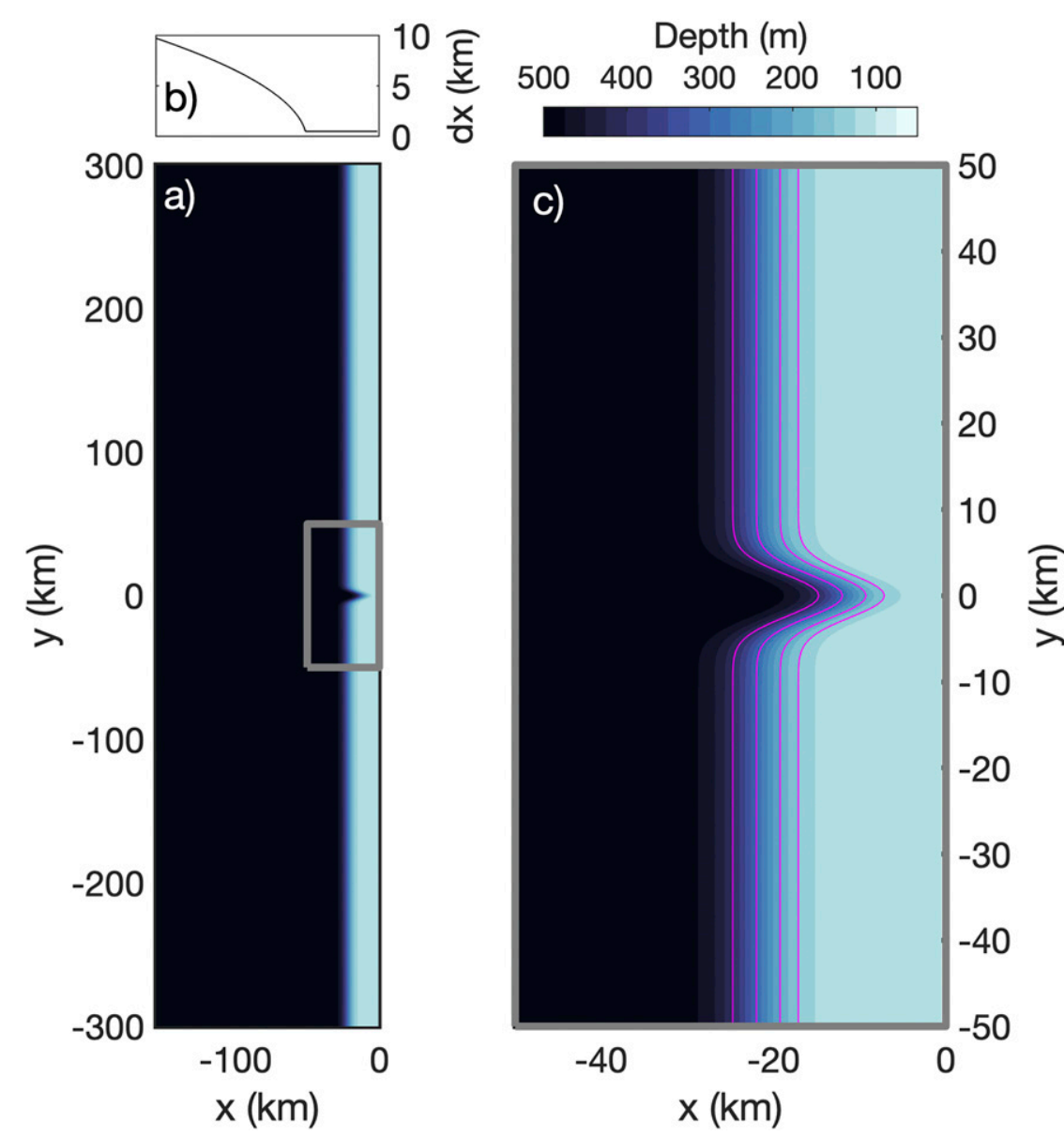

FIG. 1. (a) Model domain bathymetry (colors; $m$ ) with the location of the submarine canyon enclosed in a gray box and (c) shown expanded. (b) Cross-shore grid spacing-minimum grid spacing is $500 \mathrm{~m}$ nearshore in the $x$ direction and increasing offshore of $50 \mathrm{~km}$. The grid spacing in the $y$ direction is constant $(500 \mathrm{~m})$ along the whole domain. The $150,200,300$, and $400 \mathrm{~m}$ isobaths are shown in magenta contours in (c).

experiments with more realistic sloping shelves (Figs. 2b,c) by changing some key parameters in (1) and (2) (see Table 1). Vertical resolution is supplied by $30 s$-coordinate levels with increased resolution near the surface and bottom in order to resolve the surface and bottom boundary layers. The domain has three open boundaries (north, south, and offshore). Free-slip conditions are applied along the coast. On the three open boundaries, implicit gravity wave radiation conditions (Chapman 1985) are applied to the surface elevation, whereas the Flather radiation scheme (Flather 1976) is applied for depth-averaged horizontal velocities. Orlanski radiation conditions (Orlanski 1976) are applied to the baroclinic velocities, temperature, and salinity along the offshore boundary. A local twodimensional model is run in the northern and southern boundary to obtain the local boundary conditions, as in other studies of coastal upwelling (Gan and Allen 2005; Castelao and Barth 2007).
All runs are forced only with a horizontally uniform surface wind stress that is ramped up from 0 to $-0.03 \mathrm{~N} \mathrm{~m}^{-2}$ in 5 days (from day 10 to 15 ), after which it is maintained constant. We set the first 10 days of the model to run free in order to let transients decay. Initial conditions in temperature and salinity are set horizontally uniform and taken from the average profiles from all spring-summer glider observations off Oregon during the period 2006-14. Thus, our density and stratification conditions are similar to previous studies of coastal upwelling instabilities off Oregon (Durski and Allen 2005).

\section{Results}

a. Coastal upwelling: No-canyon versus canyon cases

Coastal upwelling structure in a domain with alongshore uniform bathymetry shows key differences as 

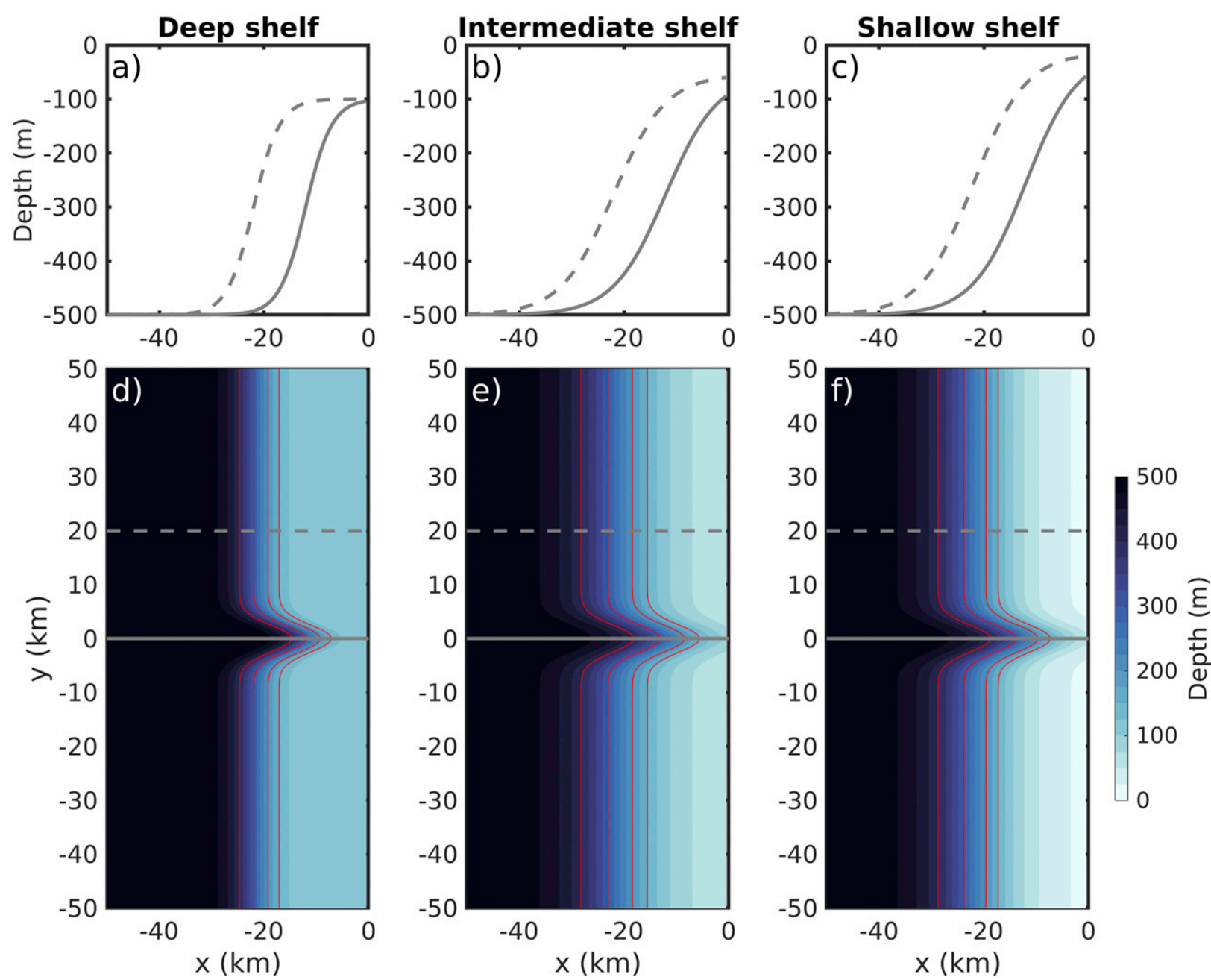

FIG. 2. (a)-(c) Cross-shore depth profiles for the three bathymetry configurations (Table 1); solid and dashed gray lines correspond to the (d)-(f) along-canyon and ambient shelf profiles, respectively. The 150, 200,300, and $400 \mathrm{~m}$ isobaths are also shown in magenta contours in (d)-(f).

function of shelf slope (Figs. 3a-c). After 10 days of upwelling-favorable winds, frontal instabilities are enhanced over deeper (and less inclined) continental shelves (Figs. 3a,b). The surface circulation (as represented by the streamlines in white) is primarily southwestward in response to wind-driven upwelling for the three shelf configurations, however, the shallow shelf case (Fig. 3c) presents less offshore-onshore fluctuations as compared to its deeper shelf counterparts (Figs. 3a,b). The presence of a submarine canyon considerably modifies the circulation and coastal upwelling structure in all cases; denser upwelling water is brought to the surface on the downstream side of the canyon (primarily for the intermediate and shallow shelf cases; Figs. 3e,f), and the surface circulation meanders over the canyons (Figs. 3d-f). Frontal instabilities seem to have a longer alongshore scale, especially downstream of the canyon (Figs. 3d-f).
Depth-averaged vertical velocity fields are shown in Fig. 4. Stripes of upward and downward flow are evident along the upwelling front and are fairly consistent with patterns of divergence and convergence of the horizontal velocity vectors (Figs. $4 a-c$ ). The presence of a submarine canyon enhances upwelling and downwelling in the area around the canyon (Figs. 4d-f). In all three canyon cases, strong upwelling is found within the canyon and on the downstream side over the shelf (Figs. 4d-f). A region of strong downwelling is also located farther south and is less pronounced in the deep shelf case (Figs. 4d-f).

\section{b. Cross-shore and alongshore upwelling structure}

The vertical structure of coastal upwelling (as seen through the velocity and density fields at day 25) differs considerably when a submarine canyon incises the 


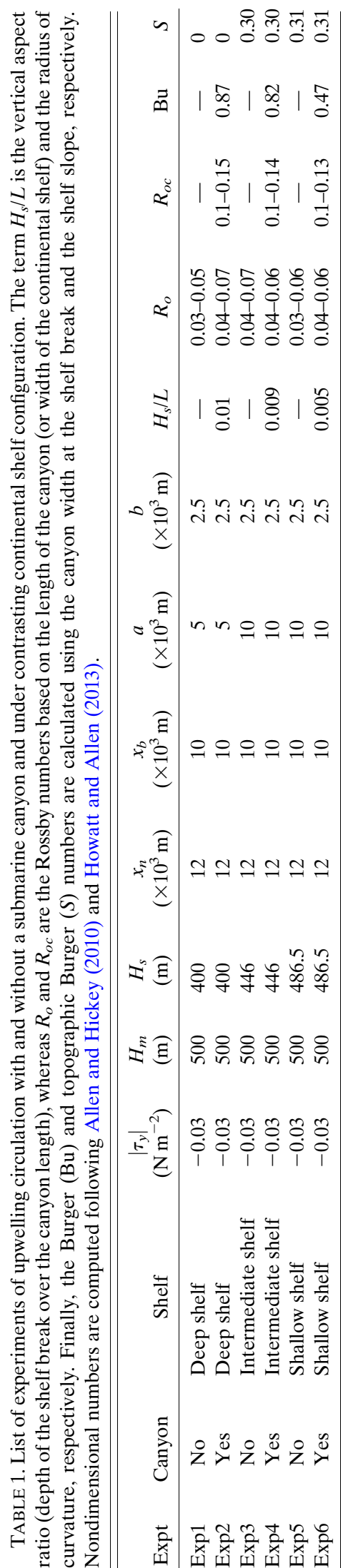

continental shelf (Fig. 5 versus Fig. 6). Minor differences occur upstream $(y=15 \mathrm{~km})$ of the canyon where upwelled isopycnals rise from about $50-70 \mathrm{~m}$ to the surface to form the upwelling front and jet (Figs. 5a-c). These differences represent some key upwelling features of the impact of a submarine canyon on the upstream circulation. Here, the upwelling jet is weaker for the cases with a submarine canyon (Figs. 6a-c), and a bottom countercurrent (northward flow) is formed near the coastal wall in the deep shelf experiment (Fig. 6a), which is not well developed in the no-canyon case (Fig. 5a). The vertical structure of frontal instabilities is evident in the cross-shore velocity fields and is enhanced over deeper shelves with an approximate vertical scale of 50-60 m (Fig. 5d versus Fig. 5f). Some frontal instabilities form in the shallow shelf case with a canyon, which are not clearly seen in the basic case without a canyon (Fig. 6f versus Fig. 5f).

As expected, the presence of a submarine canyon changes dramatically the circulation and upwelling structure in its vicinity: (i) the upwelling jet weakens in all shelf cases (Figs. 6g-i versus Figs. $5 \mathrm{~g}-\mathrm{i}$ ) and its vertical structure is partially fractured due to the cyclonic turn onshore, which is best seen in the deep shelf case (Fig. 6g versus Fig. 5g), (ii) The cross-shore flow is predominantly onshore with stronger upwelling currents at about the rim depth (Figs. 6j-1), and (iii) deep water $(150-170 \mathrm{~m})$ is transported up and onshore through the canyon, and reaches the nearshore region on the shelf (Figs. 6j-1; black contours). After the jet passes over the canyon it moves onshore and accelerates (Figs. 6m-O versus Fig. 5m-o). As seen from the depth-averaged vertical velocity fields (Figs. 4d-f), more upwelling occurs nearshore over the shelf but strong downward velocities dominate in an area farther downstream in the continental shelf (Figs. 4d-f), which is characterized vertically by a tongue of offshore flow extending down to the shelf break (Figs. $6 p-r$ versus Figs. $5 p-r$ ).

Alongshore sections of density and cross-shore flow along the upwelling jet show impacts of the canyon in upwelling structure, cross-shore exchanges, and the vertical structure of the frontal instabilities (Fig. 7). The canyon increases, to a large extent, the presence of upwelled denser waters along the downstream side of the canyon (Figs. 7d-f versus Figs. 7a-c). This enhanced upwelling is also characterized by the stretching of water parcels inside the canyon, which is consistent with the onshore turning of the flow (Figs. 7j-1). The presence of a submarine canyon also changes the vertical structure of the frontal instabilities. They are fairly well organized in an offshore/onshore flow pattern extending through most of the water column (Figs. 7g-i). The upstream characteristics do not change significantly when a 

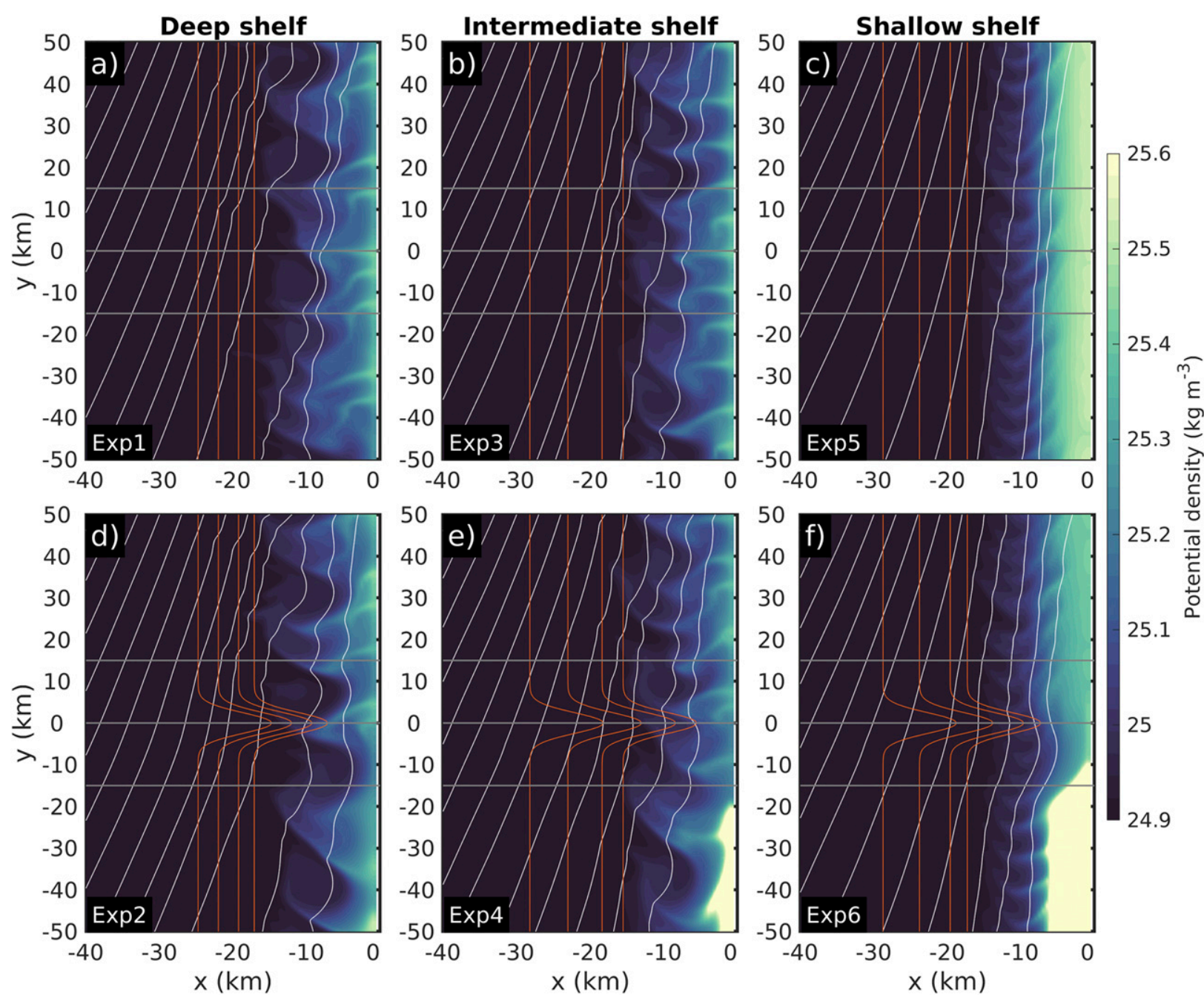

FIG. 3. Upwelling filaments as seen in surface potential density fields (in color) for (a)-(c) no-canyon and (d)-(f) canyon experiments with contrasting continental shelves at day 25 . The isobaths of $150,200,300$, and $400 \mathrm{~m}$ are shown in orange contours, whereas the surface circulation is illustrated with white streamlines for each case. Horizontal gray lines denote the location of cross-shore sections shown in Figs. 5 and 6. Surface flow is offshore and downwind, consistent with Ekman theory. Instabilities occur on the upwelling jet and are significantly impacted by the presence of a canyon.

canyon is introduced into the system, however, the flow on the downstream side is dramatically modified; the onshore upwelling flow over the canyon can extend up to the surface, and downwelling/offshore currents dominate downstream around $10-30 \mathrm{~km}$ south of the canyon (Figs. $7 \mathrm{j}-1$ ).

\section{c. Characteristics of frontal instabilities and energetics}

The phase of the frontal disturbance propagates southward in the direction of the mean flow as shown by the depth-averaged cross-shore velocity along the core of the jet between 8 and $10 \mathrm{~km}$ offshore (Fig. 8, left panels). The small-scale patterns that appear to dominate at the onset of the frontal instability grow to larger wavelengths during the last 3-4 days of the runs (see Figs. 8a,g). To quantify these changes of the dominant alongshore scales, a wavelet power spectrum (WPS) is shown for the days 21 and 25 along the same sections at $x=-8$ and $-10 \mathrm{~km}$ (Fig. 8, center and right panels). We followed the widely used code by Torrence and Compo (1998) with the power spectra rectified as in Liu et al. (2007). Short wavelengths of about $8-12 \mathrm{~km}$ dominate during day 21 (Figs. 8b,h). The growth into larger wavelengths is observed by day 25 with a wider range of alongshore scales from 8 to about $28 \mathrm{~km}$ (Figs. $8 \mathrm{c}, \mathrm{i}$ ). The influence of a submarine canyon is primarily evidenced by the difference of dominant alongshore scales on the two sides of the canyon, and also by the intrusion of longer scales around the canyon in association with the background canyon circulation. Frontal instabilities are characterized by similar features (as no-canyon 

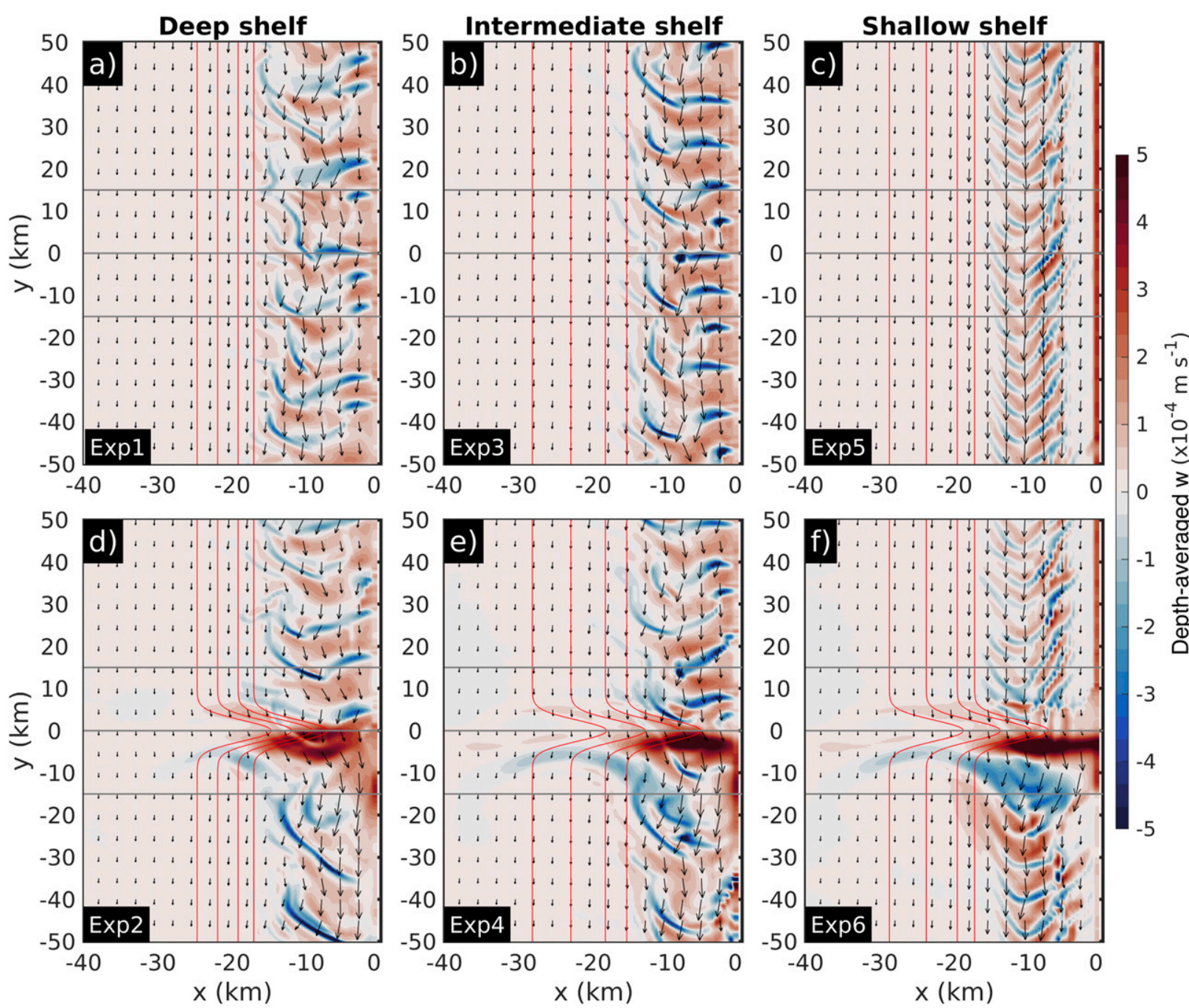

FIG. 4. Upwelling and downwelling regions as seen in depth-averaged vertical velocity fields (in color) for (a)-(c) no-canyon and (d)-(f) canyon experiments with contrasting continental shelves at day 25 . The isobaths of $150,200,300$, and $400 \mathrm{~m}$ are shown in red contours. The depthaveraged horizontal velocity field is shown in black vectors. Horizontal gray lines denote the location of cross-shore sections shown in Figs. 5 and 6. Note the locations of the core of the upwelling jet is about $x=-8 \mathrm{~km}$ for the deep and intermediate shelf, and at about $x=-10 \mathrm{~km}$ for the shallow shelf. These locations are used in Figs. 7 and 8. Depth-averaged velocity shows onshore/offshore flow due to both the instabilities and the canyon, and clearly shows the impact of the canyon on strengthening the instabilities downstream of the canyon.

experiments) on the upstream side but are considerably larger on the downstream side ( $\sim 20-30 \mathrm{~km}$; Figs. 8f,1).

Perturbation fields are decomposed, similar to other studies (e.g., Durski and Allen 2005; Brink 2016a), to analyze the evolution of the perturbation vorticity field and the conversion of energy, as follows:

$$
\begin{aligned}
q(x, y, z, t) & =\bar{q}+q^{\prime}, \\
\bar{q}(x, z, t) & =\frac{1}{L_{y}} \int_{L_{i}}^{L_{f}} q d y,
\end{aligned}
$$

where $q$ is the density or a velocity component ( $\rho, u, v$, or $w), \bar{q}$ and $q^{\prime}$ are its alongshore average and perturbation, respectively. It is important to emphasize that the perturbation calculation is with respect to the alongshore average and not the time average as in other studies (Kang and Curchitser 2015). Thus, the near steady response to the canyon appears primarily in the eddy terms for the downstream region as it is shown later in the energetics. The alongshore scale is defined here as $L_{y}$, which is the distance from an initial $L_{i}$ to final $L_{f}$ alongshore extension of the model domain. Thus, the perturbation vorticity field is calculated as

$$
\zeta^{\prime}=\frac{\partial v^{\prime}}{\partial x}-\frac{\partial u^{\prime}}{\partial y}
$$




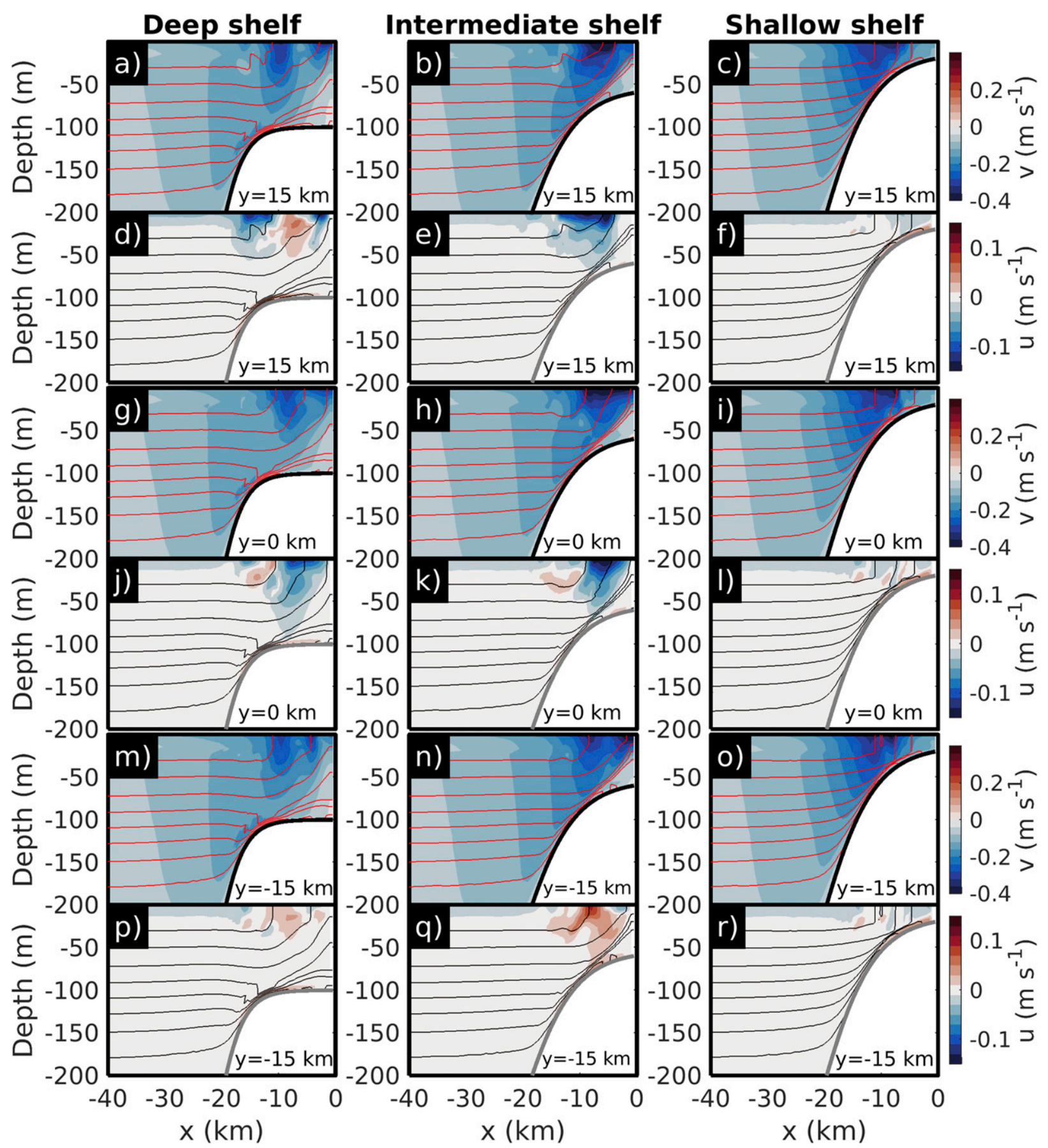

FIG. 5. Cross-shore sections of the velocity (colors) and density (red and black contours) fields at (a)-(f) $y=15 \mathrm{~km},(\mathrm{~g})-(\mathrm{l}) y=0 \mathrm{~km}$, and (m)-(r) $y=-15 \mathrm{~km}$ showing the structure of coastal upwelling for the three bathymetry configurations without a submarine canyon (Exp1, Exp3, and Exp5) at day 25.

The evolution of the surface $\zeta^{\prime}$ field adds additional insights about the formation of frontal instabilities and the influence of a submarine canyon on their evolution (Fig. 9) as compared to previous studies without the presence of a canyon (Durski and Allen 2005). The generation of the instabilities is clearly seen by day 18 for the deep shelf experiments, and these instabilities are characterized by tilting downstream and offshore (Fig. 9b). The presence of the canyon disrupts their early development downstream and increases the anticyclonic perturbation vorticity over this region (Fig. 9f). By day 20 the instabilities have already curved backward on 


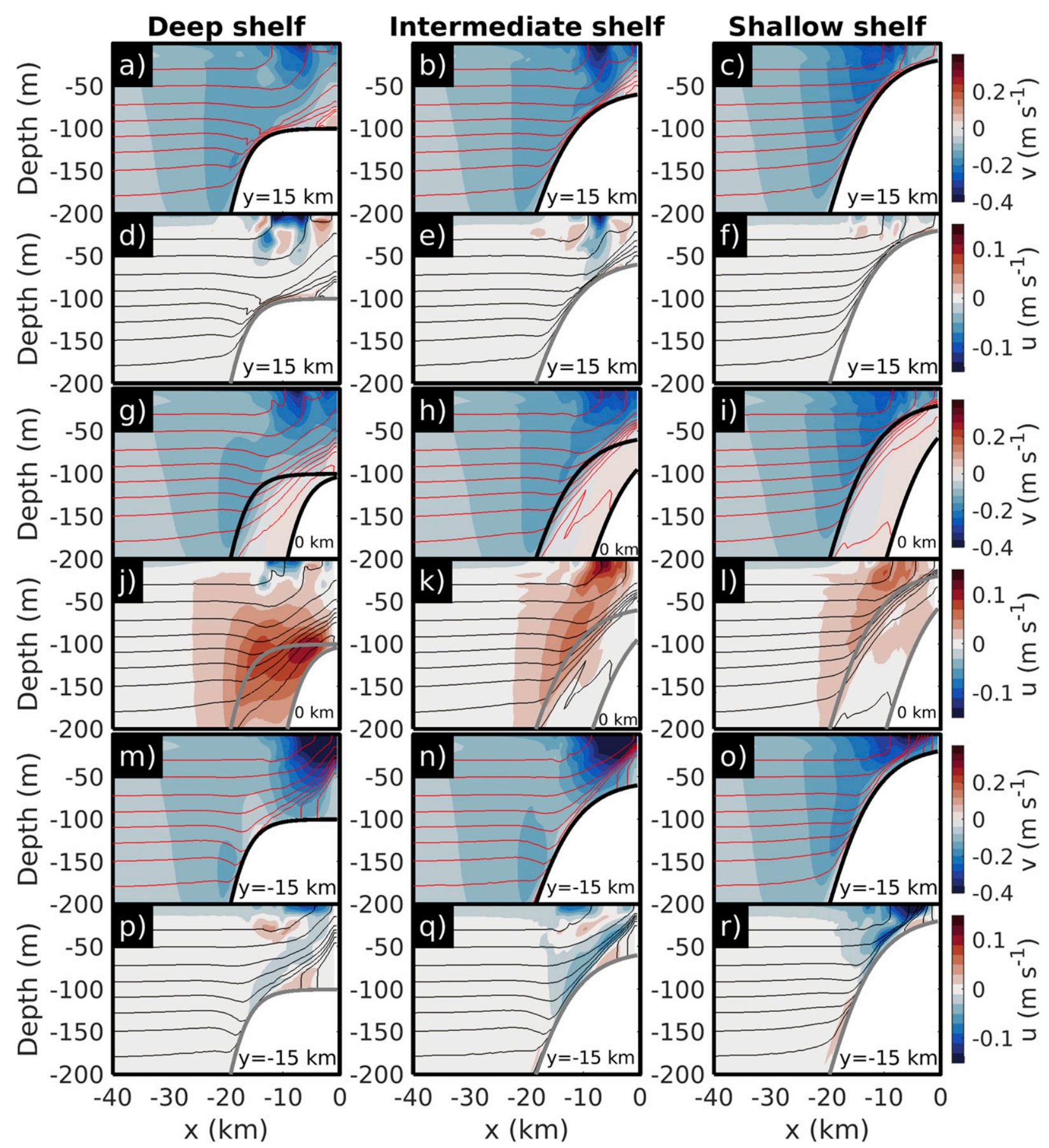

FIG. 6. Cross-shore sections of the velocity (colors) and density (red and black contours) field at (a)-(f) $y=15 \mathrm{~km},(\mathrm{~g})-(\mathrm{l}) y=0 \mathrm{~km}$, and (m)-(r) $y=-15 \mathrm{~km}$ showing the structure of coastal upwelling for the three bathymetry configurations with a submarine canyon (Exp2, Exp4, and Exp6) at day 25.

their offshore side (Figs. 9c,g), and have formed downstream of the canyon. However, they have greater alongshore separations (i.e., wavelength) than those located north of the canyon (Fig. 9g), as was already shown by the WPS. By day 25 the upper ocean of the continental shelf is completely influenced by the instabilities with characteristic long stripes of positive vorticity. The submarine canyon impacts the characteristics of the instabilities by increasing their alongshore scale and promoting a region of negative vorticity next to the canyon (downstream side; Figs. 9h,p versus Figs. 9d,1). Key differences are also identified in the 

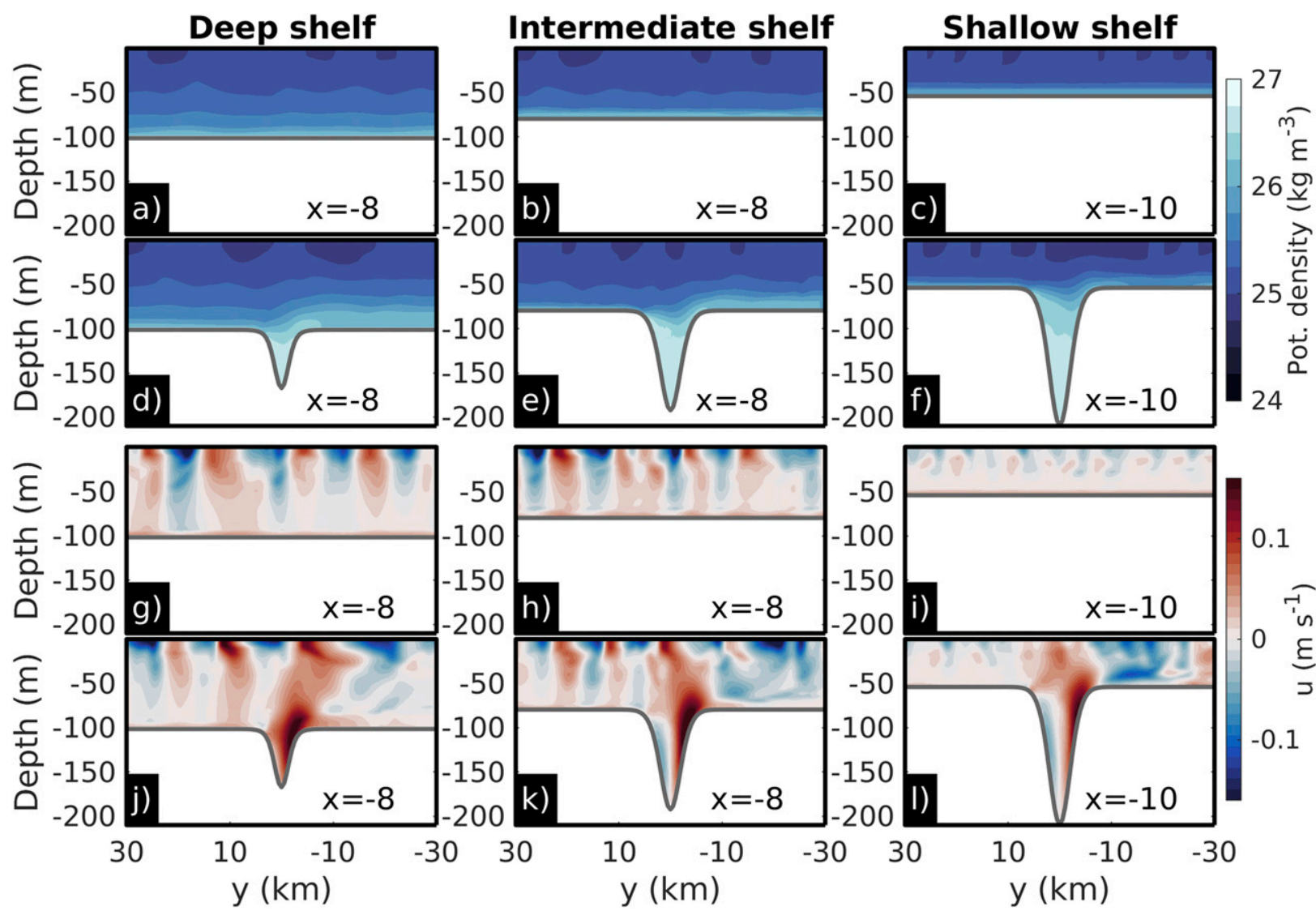

FIG. 7. Alongshore sections of (a)-(f) potential density and (g)-(l) cross-shore velocity fields along the core of the upwelling jet (at $x=-8$ and $-10 \mathrm{~km}$ ), showing the density structure and cross-shore exchanges for all experiments at day 25 . Positive cross-shore velocities in $(\mathrm{g})-(\mathrm{l})$ mean onshore flow.

shallow shelf cases with respect to the former deep shelf description. The formation of the surface instabilities takes longer (Figs. 9i-1), and the influence of the submarine canyon has a greater impact not only over the downstream side but also on the upstream side where bands of positive and negative perturbation vorticity are generated earlier as seen by day 15 (Fig. $9 \mathrm{~m}$ ). The formation of the instabilities by day 20 also differs considerably over the upstream region since enhanced negative vorticity bands are only found when there is a canyon in the shallow shelf case (Fig. 9o versus Fig. 9k). Finally, the downstream cyclonic/anticyclonic vorticity areas are formed early during the ramp-up time (days 10-15). Note that the marked band of cyclonic vorticity delimits the region of intense downstream upwelling (see Fig. 3f).

The conversion of energy provides clarifying information on the source of energy and the type of instabilities being developed. Following Kang and Curchitser (2015), the conversions of (i) mean potential energy to mean kinetic energy (PmKm), (ii) mean potential energy to eddy potential energy (PmPe), (iii) eddy potential energy to eddy kinetic energy (PeKe), and (iv) mean kinetic energy to eddy kinetic energy ( $\mathrm{KmKe})$, and the energy reservoirs (MPE, EPE, MKE, and EKE) are calculated as

$$
\begin{aligned}
\text { PmKm } & =\int_{0}^{X} \int_{-H}^{0}-g \overline{\rho_{a}} \bar{w} d z d x, \\
\text { PmPe } & =\int_{0}^{X} \int_{-H}^{0}-\frac{g^{2}}{\rho_{o} N^{2}}\left(\frac{\partial \overline{\rho_{a}}}{\partial x} \overline{u^{\prime} \rho_{a}^{\prime}}+\frac{\partial \overline{\rho_{a}}}{\partial z} \overline{w^{\prime} \rho_{a}^{\prime}}\right) d z d x,
\end{aligned}
$$

$$
\mathrm{PeKe}=\int_{0}^{X} \int_{-H}^{0}-g \overline{w^{\prime} \rho_{a}^{\prime}} d z d x
$$

$$
\begin{aligned}
\mathrm{KmKe}= & \int_{0}^{X} \int_{-H}^{0}-\rho_{o}\left(\frac{\partial \bar{v}}{\partial x} \overline{u^{\prime} v^{\prime}}+\frac{\partial \bar{v}}{\partial z} \overline{w^{\prime} v^{\prime}}+\frac{\partial \bar{u}}{\partial x} \overline{u^{\prime} u^{\prime}}\right. \\
& \left.+\frac{\partial \bar{u}}{\partial z} \overline{w^{\prime} u^{\prime}}\right) d z d x, \\
\mathrm{MPE}= & \int_{0}^{X} \int_{-H}^{0} \frac{g^{2} \overline{\rho_{a}^{2}}}{2 \rho_{o} N^{2}} d z d x, \\
\mathrm{EPE}= & \int_{0}^{X} \int_{-H}^{0} \frac{g^{2} \overline{\rho_{a}^{\prime 2}}}{2 \rho_{o} N^{2}} d z d x,
\end{aligned}
$$




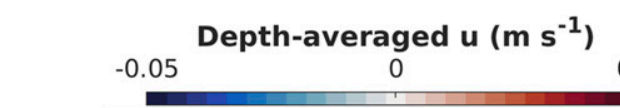

0.05
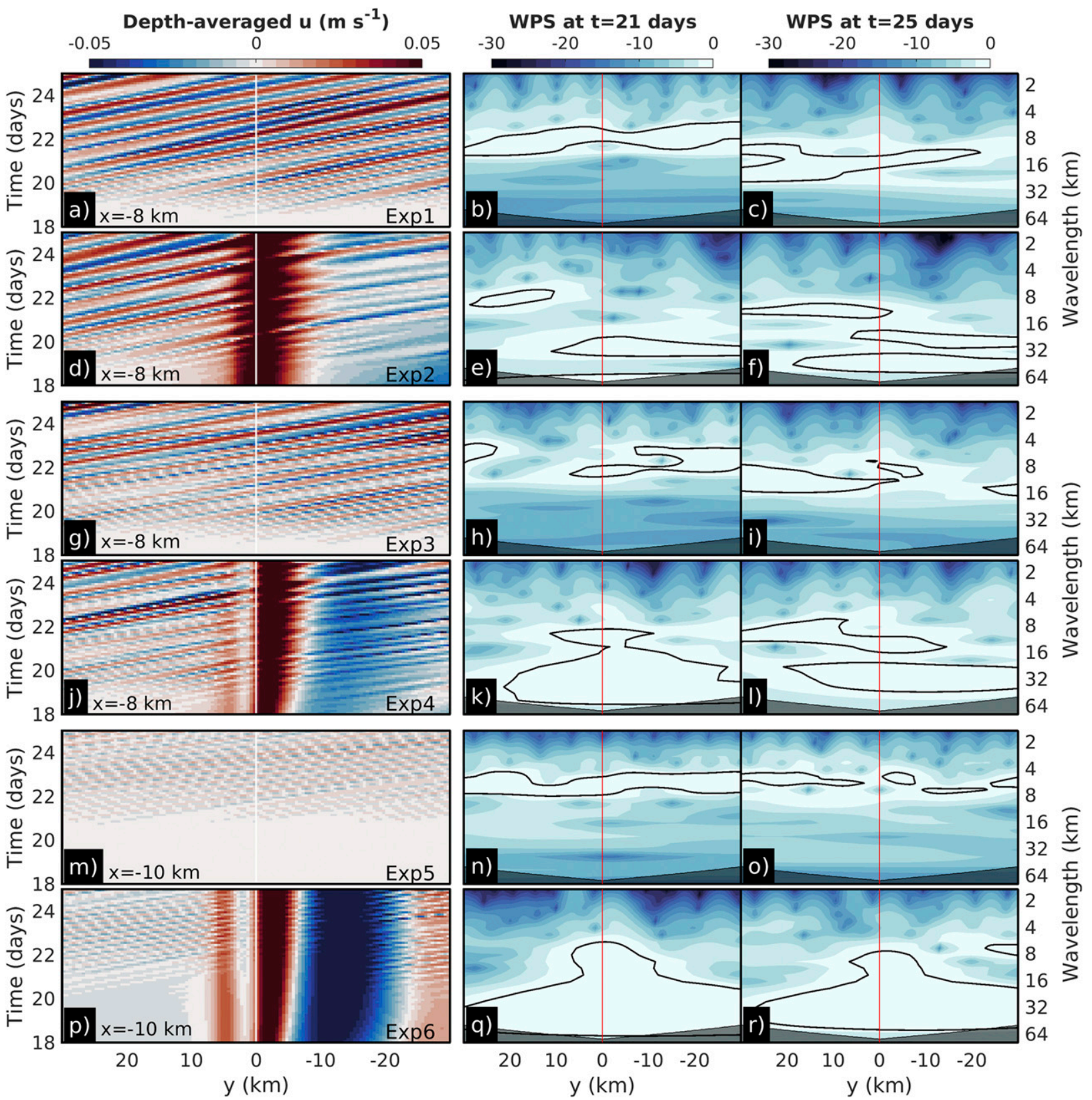

FIG. 8. Evolution of cross-shore exchanges as seen in (left) Hovmoller diagrams of depth-averaged cross-shore velocities along the core of the upwelling jet. Quantification of dominant alongshore scales of variability from a wavelet power spectrum (WPS) of depth-averaged cross-shore velocities (from the left panels) at times (center) 21 and (right) 25 days. The color of the WPS is the base 2 logarithm of power spectral density $\left(\mathrm{m}^{2} \mathrm{~s}^{-2}\right.$; scale at top). Enclosed light blue areas in the WPS denote dominant wavelengths along the upwelling front ( $95 \%$ significance). Shaded gray regions at the bottom of each panel indicate the cone of influence where edge effects become important. The instability shows increased wavelengths downstream of the canyon.

$$
\begin{aligned}
\text { MKE } & =\int_{0}^{X} \int_{-H}^{0} \frac{1}{2} \rho_{o}\left(\bar{u}^{2}+\bar{v}^{2}\right) d z d x, \quad \text { and } \\
\text { EKE } & =\int_{0}^{X} \int_{-H}^{0} \frac{1}{2} \rho_{o}\left(\overline{u^{\prime 2}+v^{\prime 2}}\right) d z d x,
\end{aligned}
$$

where $\rho_{a}$ is the perturbation density calculated as the total density minus a reference density $\left[\rho_{a}(x, y, z, t)=\rho(x, y, z, t)-\rho_{r}(z)\right]$.
Here $\rho_{r}$ is the density field from the initial conditions and $X=-30 \mathrm{~km}$ is the offshore extension of the integrals.

Once the wind is turned on there is available mean kinetic energy to be converted to mean potential energy that is evident from the increasing negative PmKm term (Fig. 10, left panels). Consequently, there is a persistent gain of MPE (larger on the downstream side) (Fig. 10, 

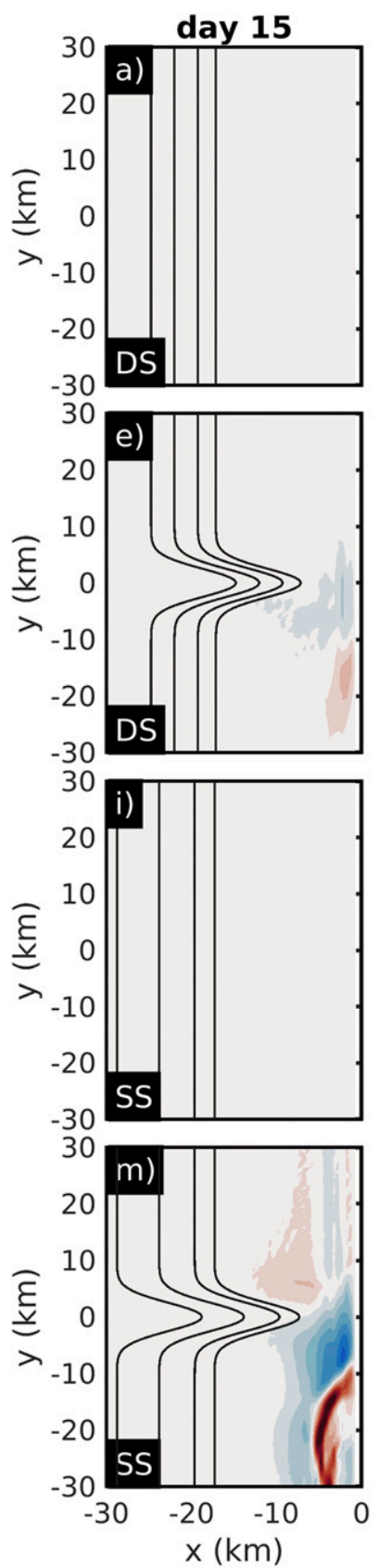
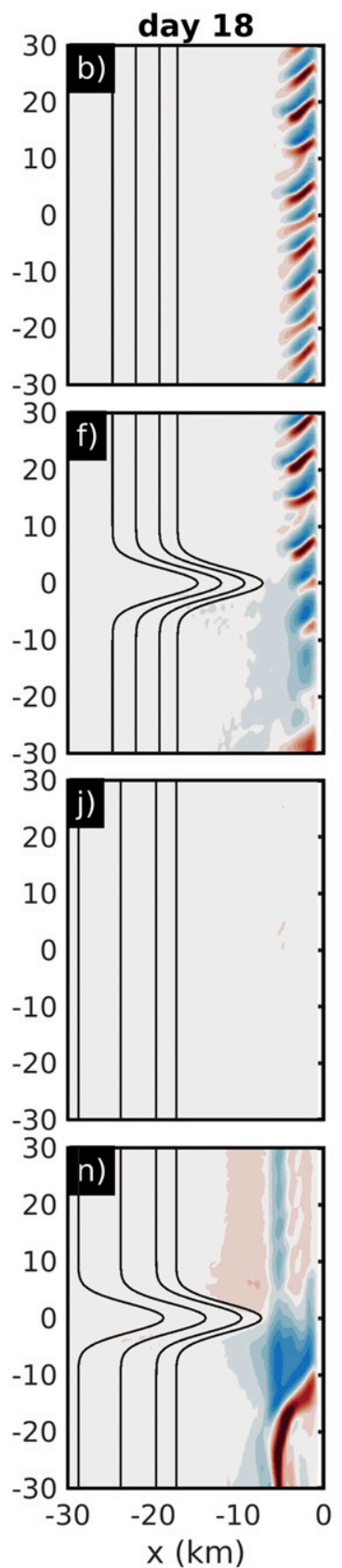
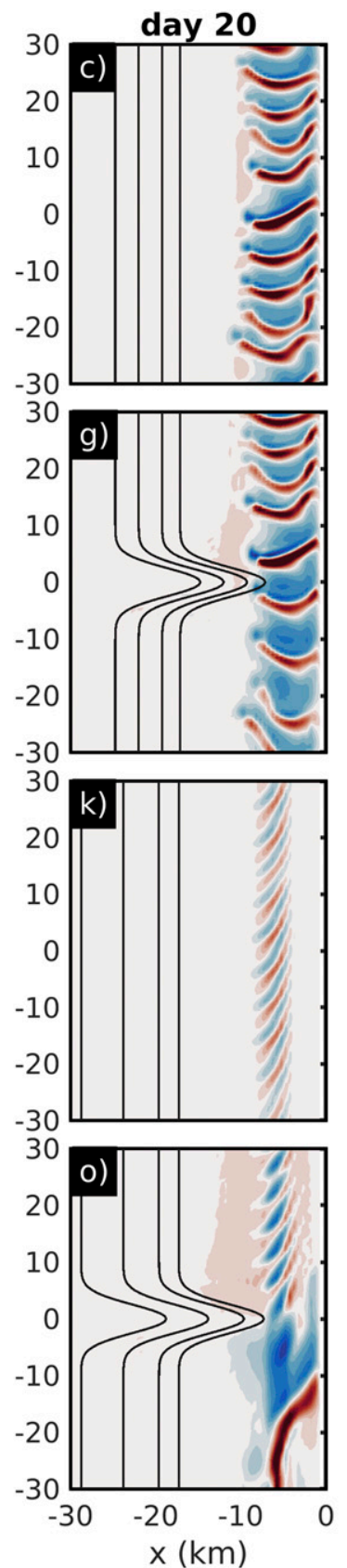

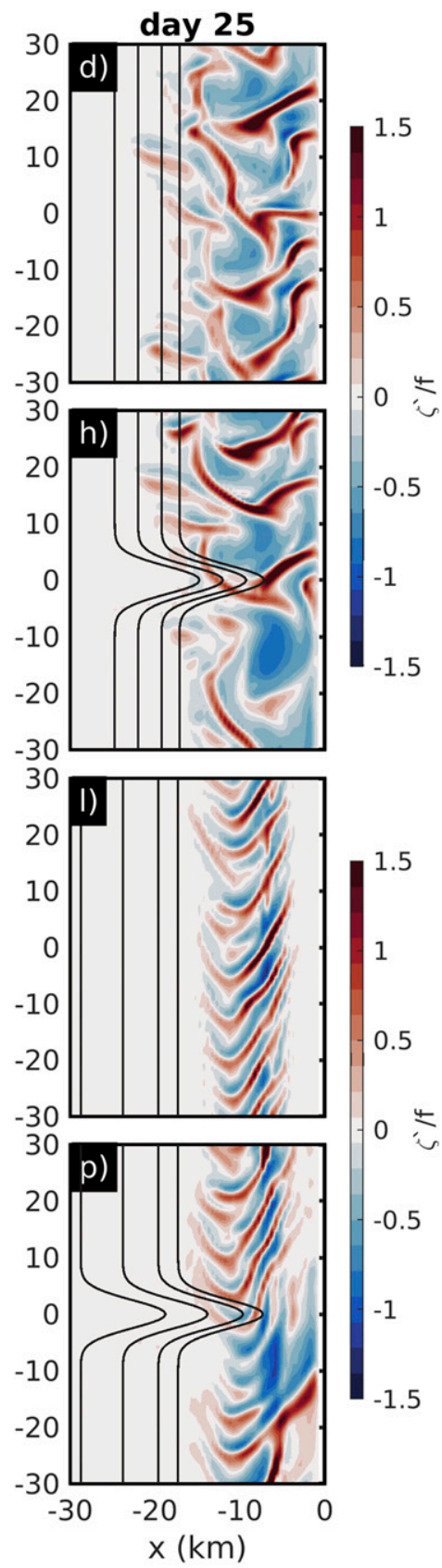

FIG. 9. Evolution of surface (for the first sigma level) perturbation vorticity field [Eq. (5)] normalized by $f$ for deep shelf (DS) and shallow shelf (SS) experiments. The isobaths of $150,200,300$, and $400 \mathrm{~m}$ are shown in black contours. The presence of a submarine canyon produces areas with contrasting vorticity, especially in the SS case.

right panels). The conversions of energy are similar for the deep and intermediate shelf cases, with the exception of a larger fluctuation in PmPe (even turning negative; with conversion from EPE to MPE) during days 22 and 23 (Fig. 10c). All conversions to eddy potential and eddy kinetic energy start about day $17-18$ when the frontal instabilities start to form. In both cases there is an increase of EPE on the downstream side but is lower than the MKE reservoir (Figs. 10b,d). The shallow shelf case differs considerably from the previous two bathymetric configurations in that the PmPe conversion is persistently negative (conversion from EPE to MPE) and starts early in the simulation (about day 14; Fig. 10e). Thus, there is a massive gain of MPE as a consequence of the canyon circulation before the start of the development of frontal instabilities, and the EPE 

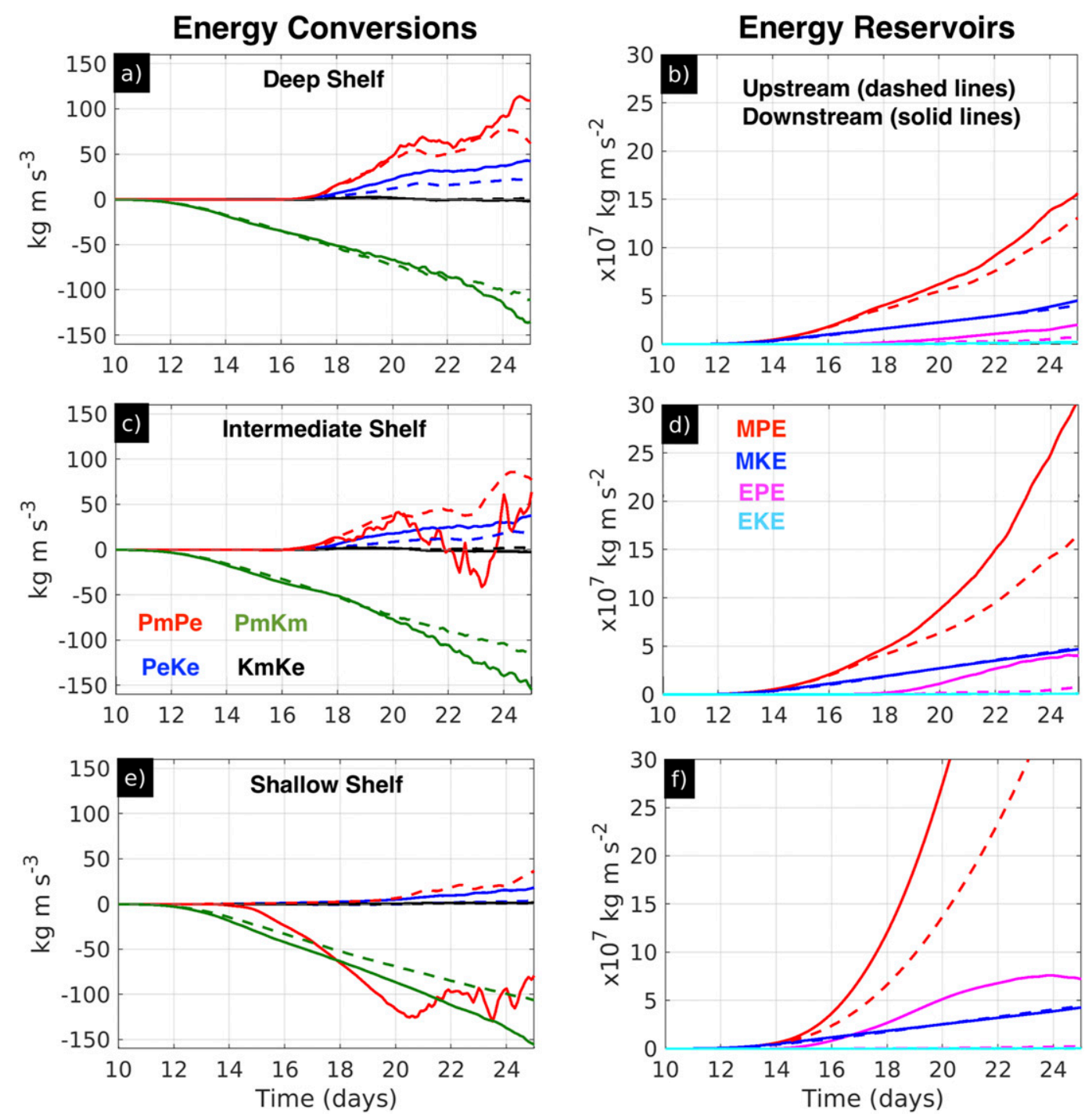

FIG. 10. (left) Energy conversions and (right) energy reservoirs for (a),(b) deep shelf, (c),(d) intermediate shelf, and (e),(f) shallow shelf experiments with a submarine canyon. The energetics have been separated for upstream $(20<y<200)$ and downstream $(-200 \mathrm{~km}<y<-20 \mathrm{~km})$ regions in each case.

becomes larger than the MKE (Fig. 10f). The evolution of PeKe and $\mathrm{KmKe}$ for deep shelf and shallow shelf cases are presented in Fig. 11 as function of cross-shore direction and time (integration only by depth through the upper half of the water column) to further visualize details of the conversions to EKE, which are the smallest conversion terms in Fig. 10. These calculations are presented for the upper half of the water column, and in a smaller area on either side of the canyon, in order clarify these conversion terms in the upper ocean where the instabilities are more intensified. For no-canyon cases, both deep and shallow shelf (DS and SS, respectively) experiments reveal a dominant conversion from eddy potential to eddy kinetic energy $(\mathrm{PeKe})$ from about day
18 to the end of the runs (Figs. 11a,e,i,m), which is consistent with the evolution of baroclinic instabilities. Although positive values of $\mathrm{KmKe}$ suggest some partial contribution of mean to eddy kinetic energy in the deep shelf experiment without a canyon (Figs. 11b,f), their magnitudes are considerably lower than PeKe values at the same time and cross-shore position. The presence of a submarine canyon does not change the dominance of PeKe (i.e., baroclinic instabilities) on either side of the canyon (Figs. 11c,g), however, more negative KmKe values on the downstream region (Fig. 11h) are consistent with the acceleration of the mean flow after passing over the canyon (there is conversion from eddy to mean kinetic energy). In contrast with the energetics in the 

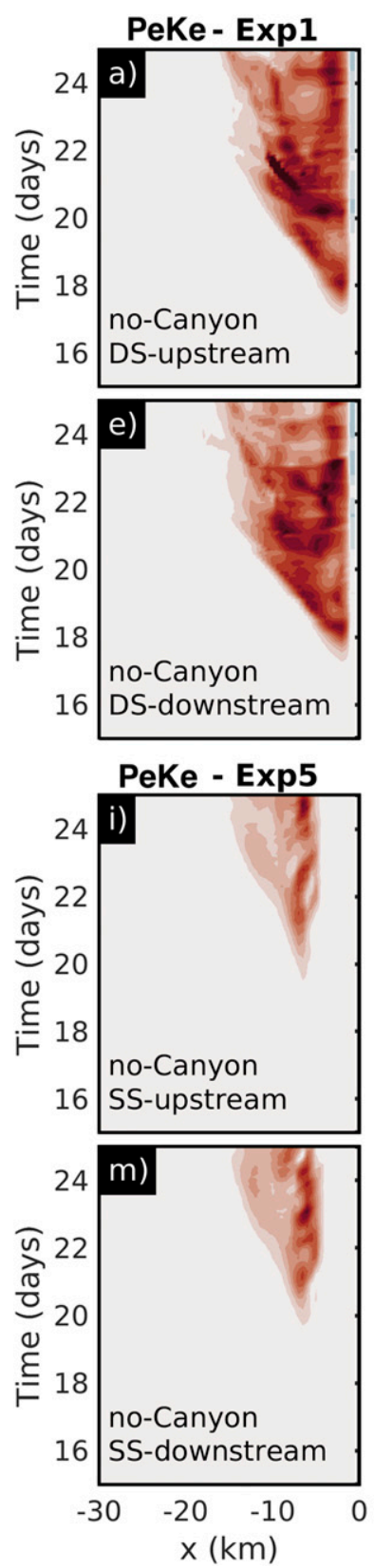

KmKe - Exp1
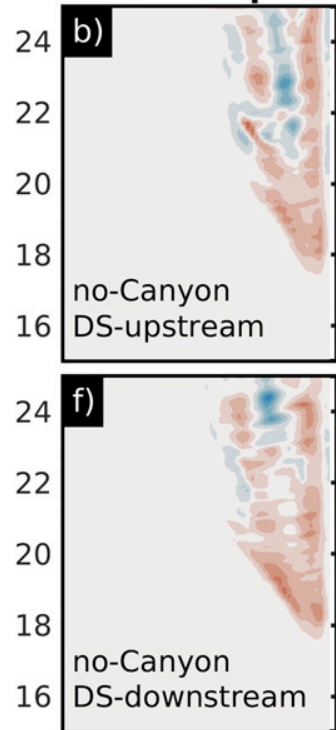

$\mathrm{KmKe}-\operatorname{Exp} 5$
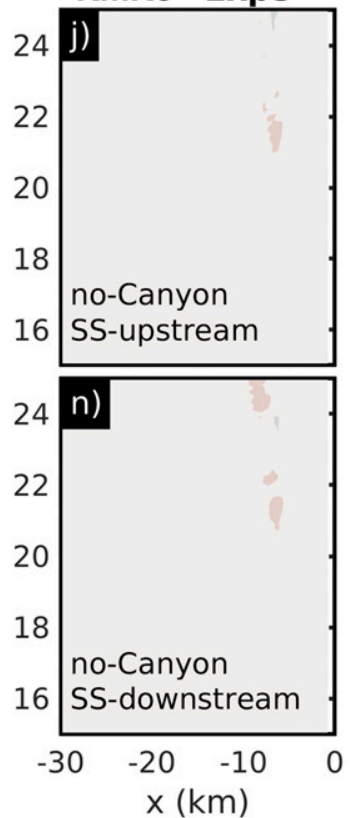
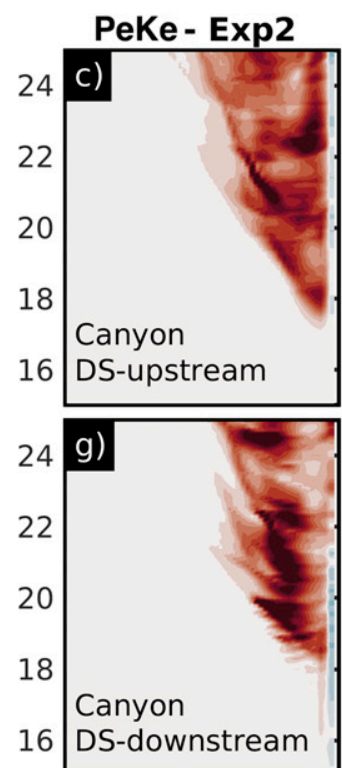

PeKe - Exp6
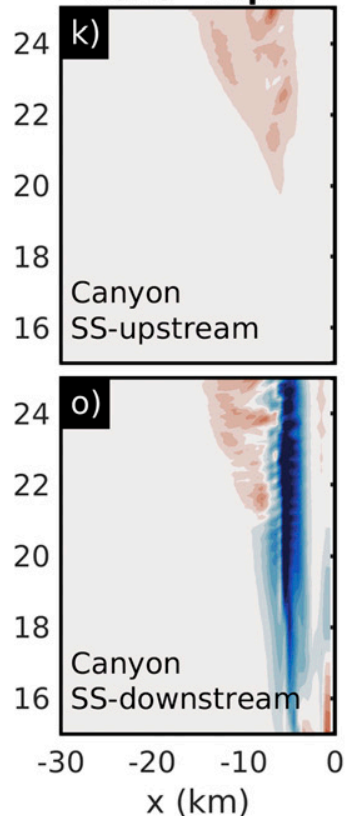
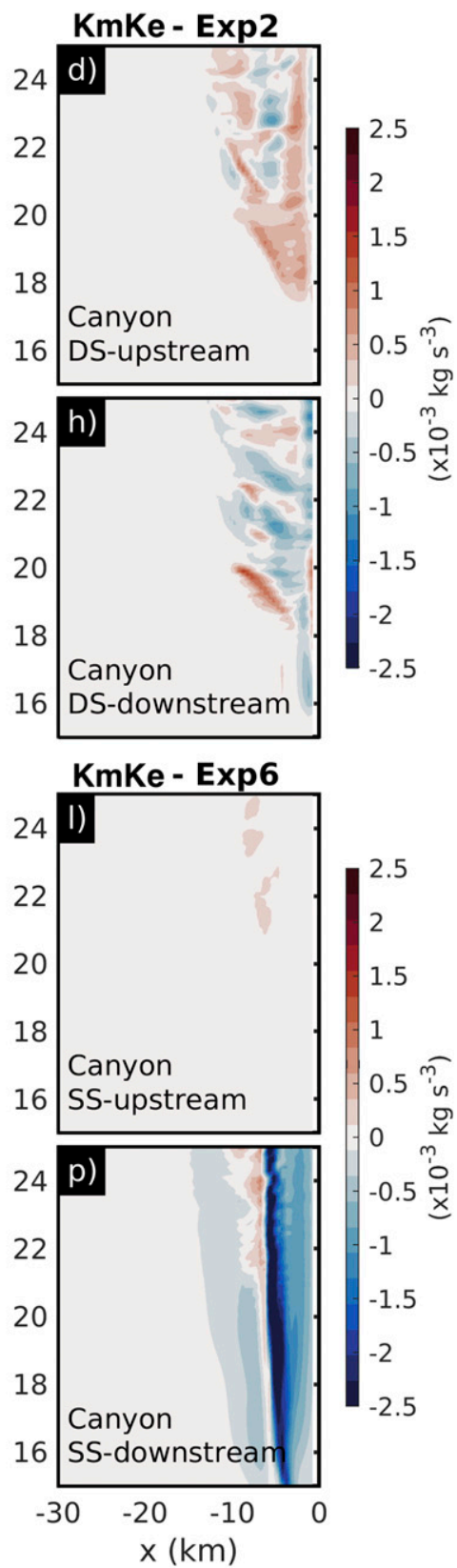

FIG. 11. Evolution of PeKe and KmKe for experiments with (Exp2 and Exp6) and without (Exp1 and Exp5) a submarine canyon for deep shelf (DS) and shallow shelf (SS) experiments. The quantification of PeKe and KmKe has been separated for upstream $(10 \mathrm{~km}<y<40 \mathrm{~km})$ and downstream $(-40 \mathrm{~km}<y<-10 \mathrm{~km})$ regions near the canyon in each case. The presence of a canyon modifies the energetics on the continental shelf, mainly downstream of the canyon in the SS case.

deep shelf canyon case, the presence of a canyon changes considerably the conversion of energy on the downstream region of the shallow shelf experiment (Figs. 11o,p). Here, the generation of baroclinic instabilities occurs only after day 21 and is restricted to the offshore side of the front (Fig. 11o). The main axis of negative PeKe and KmKe (Figs. 11o,p) agrees well with the offshore limit of intensified upwelling (Fig. 3f) and positive perturbation vorticity (Figs. $9 \mathrm{~m}-\mathrm{p}$ ); there is a gain of eddy potential energy and an acceleration of the mean flow.

\section{d. Cross-shore transports along the upwelling jet}

Considering that both frontal instabilities and a submarine canyon induce intensified cross-shore exchanges, the quantification of the transports with and without a 

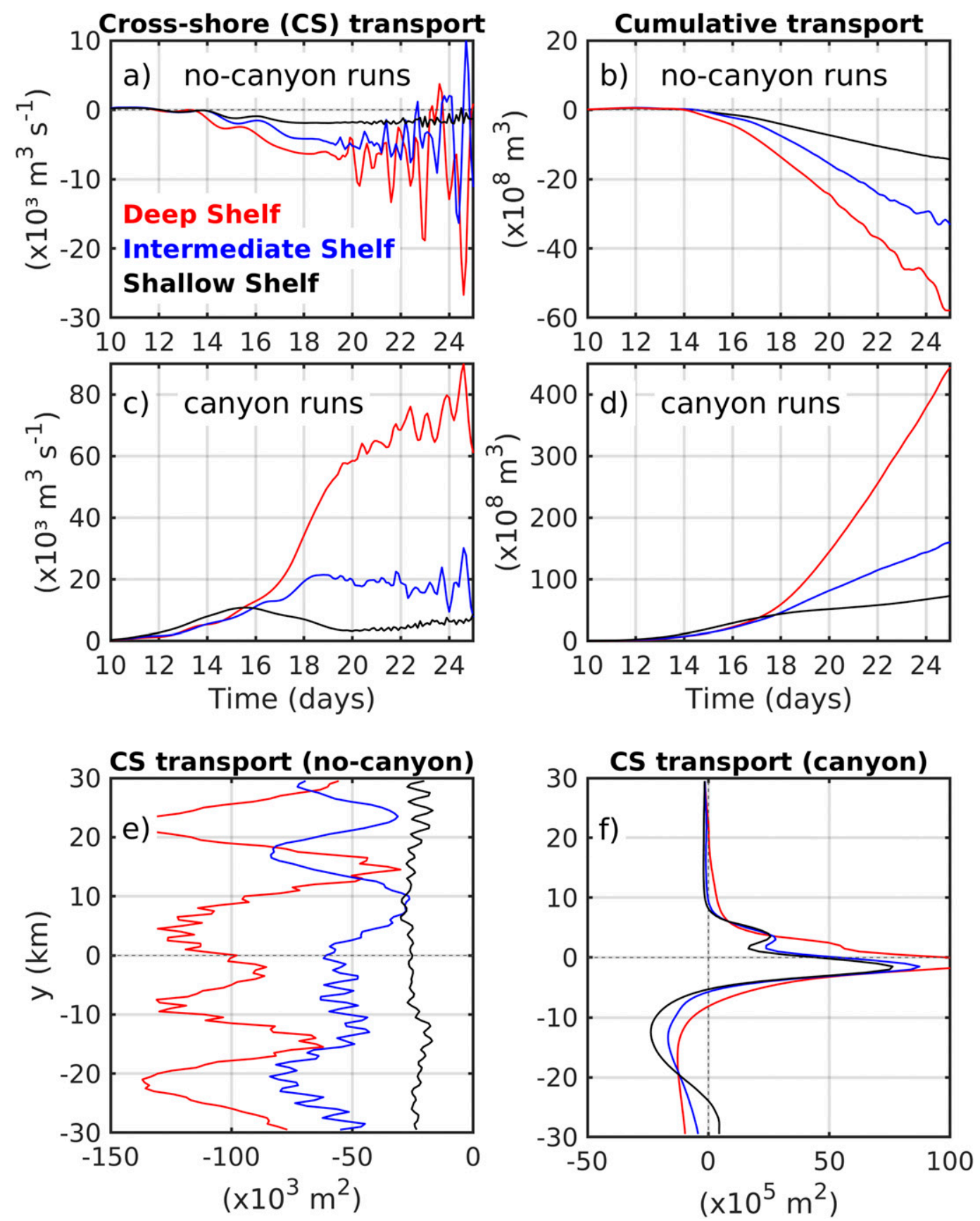

FIG. 12. (a)-(d) Cross-shore (CS) and cumulative transports through the meridional planes shown in Fig. 7 as a function of time, and (e),(f) CS transports as function of meridional distance $(-30<y<30)$ through the 25 days of runs. The transports are color coded for deep shelf (red curves), intermediate shelf (blue curves), and shallow shelf (black curves) experiments. Note the differences in scales between the left and right panels. Onshore transport is greatly enhanced in deepest shelves with a submarine canyon.

submarine canyon provides elucidating results on the competition of both effects on the net cross-shore flow under steady wind forcing (Fig. 12). When no-canyon is introduced in the system, the transport is mainly offshore in response to wind-driven coastal upwelling with low sea level nearshore (Fig. 12a). The development of frontal instabilities after about day 19 causes oscillations in the amount of water being transported offshore, and even occasional net onshore transport by the end of the deep and intermediate shelf experiments (Fig. 12a). 
Overall, these fluctuations do not change the general trend of an increasing accumulated offshore transport along the upwelling jet over time, and with an increased volume of water transported offshore in cases with deeper shelves (Fig. 12b). Thus, there is the expected net export of shelf water to the open ocean due to Ekman transport and low sea level nearshore. The presence of a submarine canyon modifies this pattern completely. As seen in Figs. $7 \mathrm{j}-1$, a submarine canyon generates intense onshore flow primarily on its downstream side, which can be spread throughout the whole water column. This results in massive onshore transport of deep/offshore water onto the continental shelf (Figs. 12b,d). The shelf slope/depth has, again, a large control on the amount of water being transported onshore, with deeper shelves having larger transports. The shallow shelf configuration result has a significant drop of the transport after day 15 (Fig. 12c). This is the result of the more intense downwelling circulation created over the downstream side of the canyon (see Fig. 4f). However, this is not enough to overcome the net onshore pattern on a regional scale. Additional calculations using an extended alongshore scale $(200 \mathrm{~km})$ reduces considerably the impact of the canyon promoting enhanced onshore transport (not shown). The alongshore variation of the onshore transport does not reveal regions with opposing trends when only frontal instabilities are considered-cross-shore transport presents alongshore fluctuations (largest for a deeper shelf) but it has a net offshore component (Fig. 12e). The canyon cases, on the other hand, are characterized by dissimilar regions of persistent onshore and offshore transports. The largest onshore flow is concentrated around the downstream half of the canyon (Fig. 12f), whereas a net offshore transport occurs farther downstream $(-30<y<-5 \mathrm{~km})$. Another upwelling region is generated south of $\sim-25 \mathrm{~km}$ but only for the shallow shelf run (Fig. 12f).

\section{Discussion}

From previous studies, the general impacts of a submarine canyon cutting across the continental shelf on the coastal circulation and exchanges can be summarized as (i) the generation of an intensified onshore transport on the downstream side of the canyon where most deep/slope water flows toward the continental shelf (Klinck 1996; Allen and Durrieu de Madron 2009; Ramos-Musalem and Allen 2019), (ii) a cyclonic circulation within the canyon (Hickey 1995; Kämpf 2007), and (iii) an onshore deflection of shelfbreak currents flowing downstream due to the gain of vorticity as the flow is stretched over the canyon (She and Klinck 2000; Allen and Durrieu de Madron 2009; Allen and Hickey 2010).
Our canyon experiments show all these aspects of the circulation associated with a canyon. Moreover, they add further insights about the circulation associated with the interaction of a canyon with the upwelling jet and its frontal instabilities; canyon-associated currents can eventually influence the entire water column (even reaching up to the surface). Here, the strong flow of the upwelling jet is deflected onshore and accelerated after passing the main canyon axis. This study confirms that, in the absence of a major bathymetric constraint such as a submarine canyon, baroclinic (the potential energy field is the primary source of perturbation kinetic energy) frontal instabilities are formed along an eastern boundary upwelling front as previous studies have shown (Barth 1989; Durski and Allen 2005; Capet et al. 2008). The influence of a canyon does not significantly perturb the characteristics of frontal instabilities upstream of the canyon as evidenced by the evolution of characteristic wavelengths and $\mathrm{PeKe}$ in cases with and without a canyon. Even though dominant wavelengths do grow in time, these would not be associated with a wave-wave interaction, as previously seen in Durski and Allen (2005), since the evolution of PeKe is always greater than $\mathrm{KmKe}$ in our noncanyon experiments. This difference might be because of the relatively short period of steady winds (10 days) in our experiments compared to the cases of Durski and Allen (2005). Our results, however, show completely new findings regarding the development and evolution of frontal instabilities over a canyon due to its unique coastal upwelling setting along an eastern boundary. Previous studies have confirmed a significant increase of cross-shore and vertical motions by the effects of the interaction of an unstable meander with a submarine canyon (Jordi et al. 2006, 2008). Nonetheless, their configuration corresponded to a coastal front typical of buoyancy-driven currents (isopycnals tilting upward in the offshore direction). Recently, the presence of arrested coastal trapped waves (CTW) on the downstream side of a shallow valley has been suggested as a dominant mechanism for the meander scale after the flow passes the valley (Zhang and Lentz 2017). This phenomenon occurs when a CTW phase speed matches the along-shelf velocity under upwelling-favorable wind conditions. Following the procedure of Zhang and Lentz (2017), solutions of phase speed for the first three CTW modes, matching the characteristic alongshore scales seen on the downstream region, are 1.5, 0.7, and $0.3 \mathrm{~m} \mathrm{~s}^{-1}$, respectively in our eastern boundary configurations. These phase speeds do not match the incoming shelf flow (about $-0.14 \mathrm{~m} \mathrm{~s}^{-1}$ ) that interacts with the canyon. Thus, the increased wavelengths found over the downstream region (Figs. 3 and 8) would not be primarily controlled by an arrested CTW. Differently from 
the study of Zhang and Lentz (2017), the frontal system of our experiments is not in quasi-steady state. Thus, the evolving meandering flow interacts with the canyon and induces fluctuations in the canyon response that may not allow the proper adjustment for the standing CTW to be formed, as in the configuration of Zhang and Lentz (2017). It is likely that the primary control on the frontal wavelengths is the increased Rossby radius of deformation $(N H / f)$ as a result of the enhanced dense water pool from canyon-induced upwelling. In fact, the evolution of shelf stratification shows higher values on the downstream side of the canyon and in deeper shelves (not shown). This control would be consistent with the theory of frontal instabilities for which wavelength scales, to a large extent, on the order of the baroclinic Rossby radius of deformation (Cushman-Roisin and Beckers 2011). These frontal instabilities $(\sim 20 \mathrm{~km})$ agree well with the second rapidly growing mode found by Barth (1994) for an eastern boundary. On the other hand, a more complicated mechanism is expected to impact these wavelengths due to the partial influence of a barotropic instability around the front (positive $\mathrm{KmKe}$ in Fig. 11). The alongshore scales of mixed barotropicbaroclinic instabilities in a shelfbreak front has been shown to depend in part on the Burger number $(\mathrm{Bu}$; e.g., Zhang and Gawarkiewicz 2015). Our canyon experiments show a high dependence on the Burger number over the downstream side of the canyon (Fig. 13), where $\mathrm{Bu}$ increases with shelf depth configuration due to higher depth and slightly higher stratification. The difference in wavelengths increases with Burger number (larger differences on deeper shelves), whereas surface density ratios decreases with Burger number since the largest density differences between downstream and upstream regions occur on shallower shelves (Fig. 13). The dominant terms of the depth-averaged cross-shore momentum equation are shown in Fig. 14 for the intermediate shelf configurations. Here, the acceleration (Accel.) is principally balanced by the sum of the horizontal advection (Adv.), Coriolis acceleration (Cor.), pressure gradient (PG), and surface (SS) and bottom (BS) stresses:

$$
\underbrace{\frac{\partial U}{\partial t}}_{\text {Accel. }}=-\underbrace{\frac{U \partial U}{\partial x}-\frac{V \partial U}{\partial y}}_{\text {Adv. }}+\underbrace{\underbrace{f V}_{\text {Cor. }}-\frac{1 \partial P}{\rho_{0} \partial x}}_{\text {Ageo. }}+\underbrace{\frac{\tau_{s}}{h \rho_{o}}}_{\text {SS }}-\underbrace{\frac{\tau_{b}}{h \rho_{o}}}_{\text {BS }},
$$

where $U$ and $V$ are the cross-shore and alongshore depth-averaged velocity components, respectively; $t$ is time; $f$ is the Coriolis parameter; $P$ is pressure; $\rho_{o}$ is a reference density; $\tau_{s}$ and $\tau_{b}$ are surface and bottom stresses; and $h$ is the water column depth. The largest

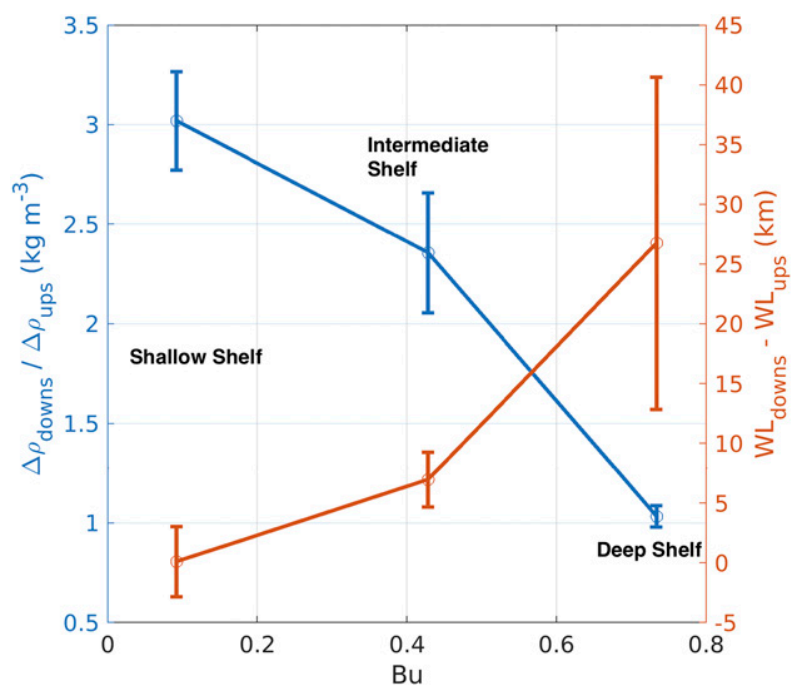

FIG. 13. Cross-canyon ratio (downstream/upstream) of crossshelf density difference (onshore-offshore), and difference in alongshore wavelengths (downstream minus upstream) as a function of Burger number $(\mathrm{Bu})$ for shallow, intermediate, and deep shelf experiments with a canyon. Average values (and their standard deviations) are calculated for the last five days of experiments when frontal instabilities are better developed. The Burger number is for the downstream shelf $\left(N H_{s} / f L\right)$, where $N$ is the average stratification over the shelf, $H_{s}$ is the depth next to the coast, $f$ is the Coriolis parameter, and $L$ is the shelf width. The cross-canyon ratio of cross-shelf density difference decreases with $\mathrm{Bu}$ whereas the difference in wavelengths increases with $\mathrm{Bu}$.

differences between the canyon and no-canyon cases are confined to the ageostrophic (Ageo.) and advection terms, which are enhanced and nearly balance each other around the canyon (Figs. 14h,l). Because the upwelling jet is primarily in thermal wind balance, the Coriolis and pressure gradient terms are also shown to highlight the impact of the canyon not only in disrupting this balance in the region above the canyon head but also its influence in decelerating the jet farther upstream and accelerating it immediately downstream and onshore of the canyon's head (Figs. 14i,j). Here, the negative ageostrophic term is due to the negative Coriolis term overcoming the positive pressure gradient (Fig. 14k). Thus, there is an ageostrophic southward flow associated with the Coriolis acceleration. Moreover, the zonal bottom stress is higher along the southern side of the canyon (Fig. 141) and reduced farther downstream in comparison with the no-canyon case (Fig. 14f). This confirms that the downstream side of the canyon is the principal area of near-bed upwelling of deep/slope water from the canyon with implications on the advection of tracers onto the continental shelf (Hickey and Banas 2008; Connolly and Hickey 2014; Ramos-Musalem and Allen 2019). However, it plays a minor role in the overall zonal momentum balance. This dynamical analysis reaffirms 

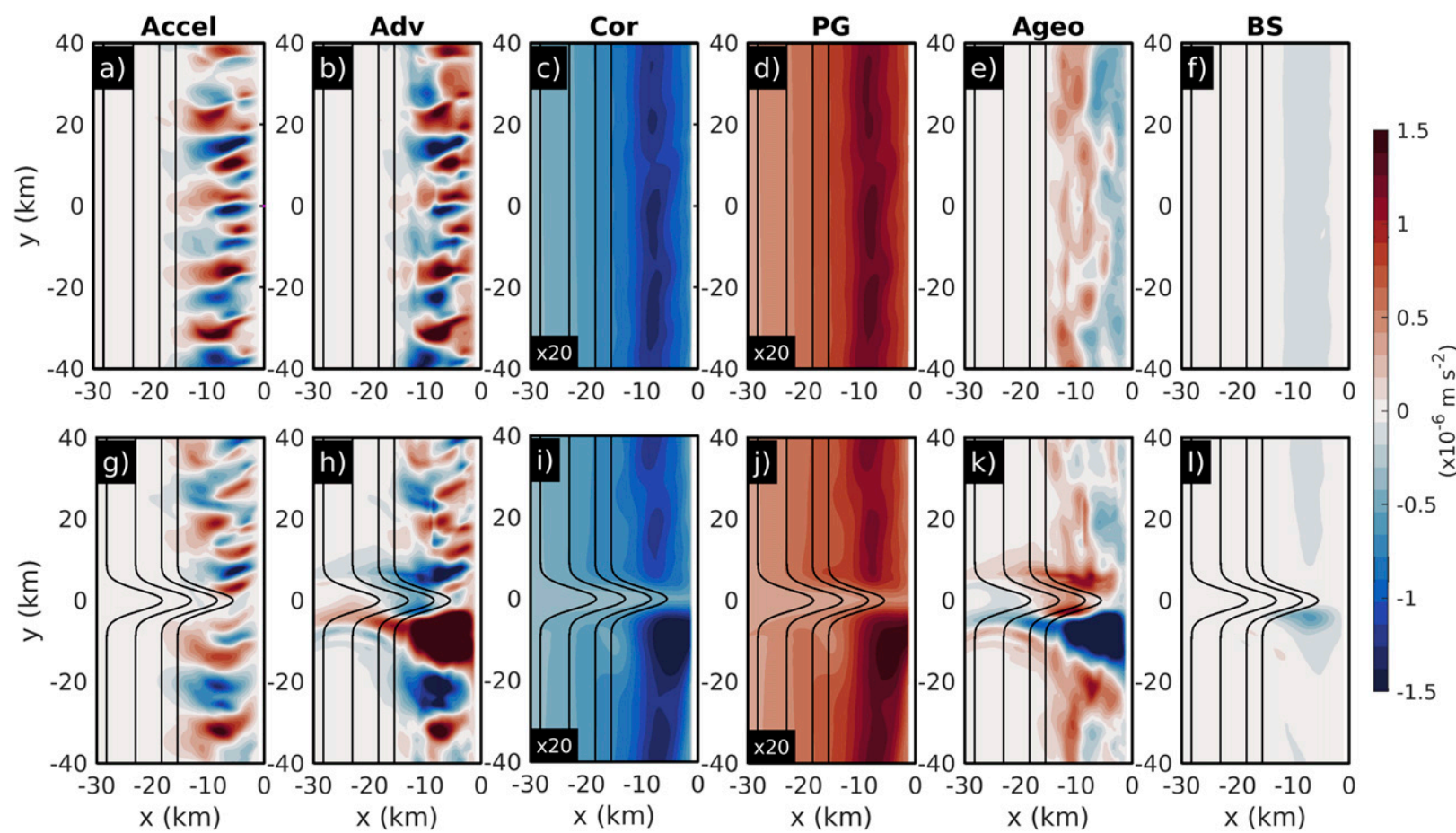

FIG. 14. Dominant terms in the depth-averaged cross-shore momentum equation [Eq. (14)] by the end of day 25 for intermediate shelf experiments (g)-(l) with (Exp4) and (a)-(f) without (Exp3) a submarine canyon. The isobaths of 150, 200, 300, and 400 $\mathrm{m}$ are shown in black contours. The terms are denoted as acceleration (Accel), advection (Adv), Coriolis (Cor), pressure gradient (PG), ageostrophic $($ Ageo $=$ Cor + PG), and bottom stress (BS). Advection and ageostrophic terms dominate both the dynamics of frontal instabilities and the circulation around the submarine canyon. The geostrophic upwelling jet decelerates (accelerates) over the upstream (downstream) region.

the crucial importance of nonlinear terms allowing intensified cross-shore exchanges by scale evolving frontal instabilities (e.g., Durski et al. 2007) or flow-topography interactions (e.g., Castelao and Barth 2006). It is still unclear how a time-dependent wind forcing would change our results. Although our steady wind forcing sets a basis for future comparisons with more realistic numerical experiments, we anticipate that considerable differences in the circulation may occur since timedependent wind forcing produces unique characteristics such as the formation of a cyclonic eddy deep within the canyon (Allen and Hickey 2010), transient pools of dense water over the shelf depending on the strength and periodicity of the wind stress (Kämpf 2006), and even downwelling currents under wind relaxation events (Hickey 1997). We also plan to inspect, in future studies, the consequences of spatially varying wind stress. A coastal band of intense wind stress curl is common in eastern boundary systems (e.g., Münchow 2000; Capet et al. 2004; Aguirre et al. 2014), which can force, in a large extent, the offshore displacement of the upwelling jet (Samelson et al. 2002; Castelao and Barth 2007; Aguirre et al. 2012). Thus, a submarine canyon and the wind stress curl field can be acting oppositely on the onshore/offshore displacement of the coastal upwelling jet in more realistic conditions. The impact of submarine canyons enhancing upwelling of deep waters over the continental shelf has been well documented (e.g., Allen and Durrieu de Madron 2009; Connolly and Hickey 2014; Sobarzo et al. 2016; Ramos-Musalem and Allen 2019). This canyon-driven upwelling is mostly confined to subsurface and bottom depths of the shelf. The frontal instabilities, however, increase the impact of the canyon at the surface (see Fig. 3). Thus, the combination of an unstable upwelling jet, promoting the development of frontal instabilities, and a submarine canyon leads to enhanced density (and implied nutrients and tracers) to the top $20 \mathrm{~m}$ of the water column (Fig. 3), which may have a significant impact on the productivity and the budget of tracers in the upper layer of the continental shelf. Upwelling waters are also characterized by low $\mathrm{pH}$ and elevated $\mathrm{CO}_{2}$ partial pressure (e.g., Torres et al. 2011; Evans et al. 2015). Thus, under enhanced upwelling conditions (i.e., as result of the combined effect of frontal instabilities over a canyon) increased $\mathrm{CO}_{2}$ outgassing occurs in regions characterized by reduced biological efficiency (uptake of $\mathrm{CO}_{2}$ is low compared to the content being upwelled) such as in the central California 

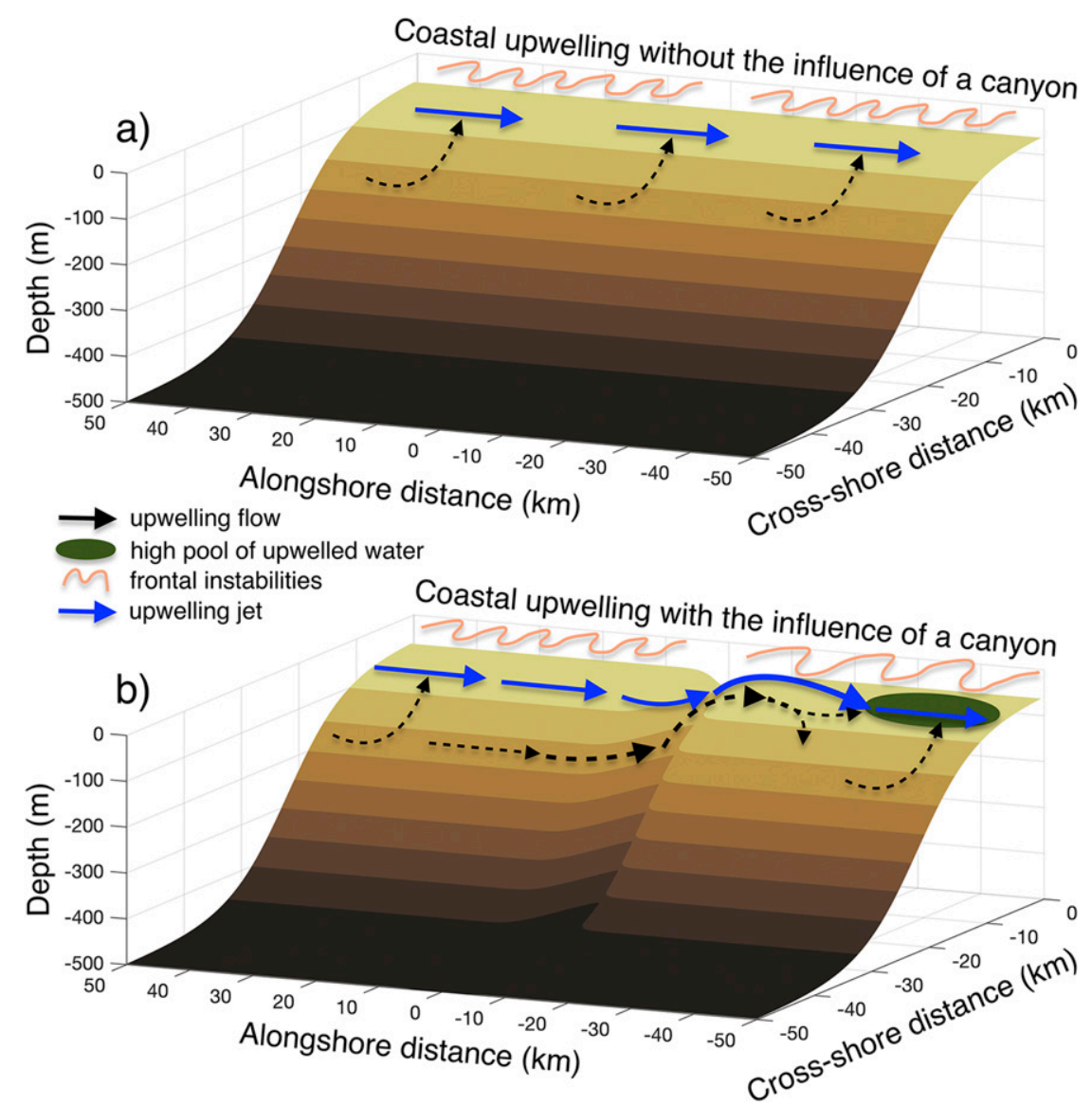

FIG. 15. Schematics of coastal upwelling in an eastern boundary (a) with and (b) without the influence of a submarine canyon. The submarine canyon influences coastal upwelling in three main aspects: (i) the inshore turn and acceleration of the upwelling jet, (ii) the generation of a downwelling area farther downstream, which is followed by a high pool of enhanced upwelled water, and (iii) the break of wavelengths in the frontal instabilities, being longer downstream of the canyon.

and the southern Canary current systems (Lachkar and Gruber 2013). Note that this should also occur with other greenhouse gases $\left(\mathrm{N}_{2} \mathrm{O}, \mathrm{CH}_{4}\right)$, which are released at high rates in eastern ocean boundaries (Kock et al. 2008; Florez-Leiva et al. 2013). Enhanced upwelling also has biological consequences near the bottom since mass die-offs of benthic organisms have been linked to upwelling-driven hypoxia/anoxia over the shelf (Grantham et al. 2004; Hernández-Miranda et al. 2012).

\section{Summary and conclusions}

Although submarine canyons and upwelling frontal instabilities (in the form of filaments and eddies) are ubiquitous features in eastern boundary current systems, process-oriented studies of the circulation and exchanges have, in general, evaluated their impacts separately. The few studies taking into consideration a canyon-front interaction were set and focused on a front with isopycnals tilted offshore (like a typical buoyancydriven flow) and a mesoscale flow that meanders over a canyon, which is a completely different scenario than the one during eastern boundary coastal upwelling. Here, a set of process-oriented numerical experiments, considering three contrasting shelf depth/slope cases, are used to study the main effects that a submarine canyon has on the circulation and cross-shore exchanges in a coastal ocean model of coastal upwelling characterized by the development of frontal instabilities. Our results show that, in the absence of a canyon, coastal upwelling forms a surface front over the shelf, which drives a baroclinic jet flowing downstream (Fig. 15a). Finite-scale baroclinic instabilities are formed and evolve around the front. Cross-shore exchanges are enhanced by these frontal instabilities, which promote spatial and temporal variability in the net offshore transport (Fig. 12). They can also produce net onshore transport at times, however, these episodes are insignificant in the accumulated transport 
over a synoptic ( $\sim 10$ days $)$ scale. A submarine canyon promotes significant changes on this dynamics since active upwelling is enhanced in the canyon with a net onshore transport (which can be orders of magnitude greater than the net offshore transport when there is no canyon; Fig. 12). Moreover, the characteristics of frontal instabilities and the perturbation vorticity field are modified by the influence of a canyon on the shelf dynamics (Fig. 9). Instabilities present increased wavelengths over the downstream region since the canyon changes the direction of the upwelling jet, changes the stratification, and sets a completely different circulation regime over the downstream region (Fig. 15b). Here, the perturbation vorticity field shows contrasting regions with a cyclonic area next to the canyon (where the flow is turned inshore) and followed by a sharp change to anticyclonic circulation in the frontal region of enhanced upwelling (particularly clear in the intermediate and shallow shelf cases). The depth-averaged cross-shore momentum balance (Fig. 14) reveals the dominance of nonlinear and ageostrophic terms in both the evolution of the frontal instabilities and the circulation around the submarine canyon, where the pressure gradient and Coriolis acceleration dominates the ageostrophic component within and downstream of the canyon, respectively. The geostrophic balance clarifies the deceleration (acceleration) of the upwelling jet on the upstream (downstream) region. We anticipate that future efforts will be focused on the inclusion of a more realistic wind stress curl field and the time dependence effects of the wind forcing.

Acknowledgments. We thank the Canyon Research Group at UBC for insightful discussions and comments. This research has been partially funded by NSERC Discovery Grant RGPIN-2016-03865 and the NSERC Accelerator DAS-492959-2016 to SEA. Computing power was provided by WestGrid and Compute Canada. GSS has been mainly funded by NSERC through a Banting Postdoctoral Fellowship. GSS is also partially supported by FONDECYT 1190805 and the Millennium Nucleus Center for the Study of Multiple-Drivers on Marine SocioEcological Systems (MUSELS) funded by MINECON NC120086. We thank two reviewers (one anonymous and John Klinck) for their valuable comments that improved the original version of this manuscript.

\section{REFERENCES}

Aguirre, C., O. Pizarro, P. T. Strub, R. Garreaud, and J. A. Barth, 2012: Seasonal dynamics of the near-surface alongshore flow off central Chile. J. Geophys. Res., 117, C01006, https://doi.org/ 10.1029/2011JC007379.

_, R. D. Garreaud, and J. A. Rutllant, 2014: Surface ocean response to synoptic-scale variability in wind stress and heat fluxes off south-central Chile. Dyn. Atmos. Oceans, 65, 64-85, https://doi.org/10.1016/j.dynatmoce.2013.11.001.

Allen, J. S., P. Newberger, and J. Federiuk, 1995: Upwelling circulation on the Oregon continental shelf. Part I: Response to idealized forcing. J. Phys. Oceanogr., 25, 1843-1866, https://doi.org/ 10.1175/1520-0485(1995)025<1843:UCOTOC $>2.0$.CO;2.

Allen, S. E., 2004: Restrictions on deep flow across the shelf-break and the role of submarine canyons in facilitating such flow. Surv. Geophys., 25, 221-247, https://doi.org/10.1007/s10712004-1275-0.

— , and X. Durrieu de Madron, 2009: A review of the role of submarine canyons in deep-ocean exchange with the shelf. Ocean Sci., 5, 607-620, https://doi.org/10.5194/os-5-607-2009.

— ing over a shelf break submarine canyon. J. Geophys. Res., 115, C08018, https://doi.org/10.1029/2009JC005731.

Alvarez, A., J. Tintoré, and A. Sabatés, 1996: Flow modification and shelf-slope exchange induced by a submarine canyon off the northeast Spanish coast. J. Geophys. Res., 101, 12043 12 055, https://doi.org/10.1029/95JC03554.

Barth, J. A., 1989: Stability of a coastal upwelling front: 2. Model results and comparison with observations. J. Geophys. Res., 94, 10 857-10 883, https://doi.org/10.1029/JC094iC08p10857.

_ 1994: Short-wave length instabilities on coastal jets and fronts. J. Geophys. Res., 99, 16095-16115, https://doi.org/ 10.1029/94JC01270.

Barton, E., D. Field, and C. Roy, 2013: Canary current upwelling: More or less? Prog. Oceanogr., 116, 167-178, https://doi.org/ 10.1016/j.pocean.2013.07.007.

Brink, K. H., 1983: The near-surface dynamics of coastal upwelling. Prog. Oceanogr., 12, 223-257, https://doi.org/10.1016/00796611(83)90009-5.

_ 2016a: Continental shelf baroclinic instability. Part I: Relaxation from upwelling or downwelling. J. Phys. Oceanogr., 46, 551-568, https://doi.org/10.1175/JPO-D-15-0047.1.

_ 2016b: Cross-shelf exchange. Annu. Rev. Mar. Sci., 8, 59-78, https://doi.org/10.1146/annurev-marine-010814-015717.

Capet, X., P. Marchesiello, and J. McWilliams, 2004: Upwelling response to coastal wind profiles. Geophys. Res. Lett., 31, L13311, https://doi.org/10.1029/2004GL020123.

_ J. C. McWilliams, M. J. Molemaker, and A. Shchepetkin, 2008: Mesoscale to submesoscale transition in the California current system. Part II: Frontal processes. J. Phys. Oceanogr., 38, 44-64, https://doi.org/10.1175/2007JPO3672.1.

Carr, M.-E., and E. J. Kearns, 2003: Production regimes in four Eastern Boundary Current systems. Deep-Sea Res. II, 50, 3199-3221, https://doi.org/10.1016/j.dsr2.2003.07.015.

Castelao, R. M., and J. A. Barth, 2006: The relative importance of wind strength and along-shelf bathymetric variations on the separation of a coastal upwelling jet. J. Phys. Oceanogr., 36, 412-425, https://doi.org/10.1175/JPO2867.1.

$\longrightarrow$, and - 2007: The role of wind stress curl in jet separation at a cape. J. Phys. Oceanogr., 37, 2652-2671, https://doi.org/ 10.1175/2007JPO3679.1.

Chapman, D. C., 1985: Numerical treatment of across-shore open boundaries in a barotropic ocean model. J. Phys. Oceanogr., 15, 1060-1075, https://doi.org/10.1175/1520-0485(1985)015<1060: $\mathrm{NTOCSO}>2.0 . \mathrm{CO} ; 2$.

Chen, X., and S. E. Allen, 1996: The influence of canyons on shelf currents: A theoretical study. J. Geophys. Res., 101, $18043-$ 18 059, https://doi.org/10.1029/96JC01149.

Chen, Z., X.-H. Yan, and Y. Jiang, 2014: Coastal cape and canyon effects on wind-driven upwelling in northern Taiwan Strait. 
J. Geophys. Res. Oceans, 119, 4605-4625, https://doi.org/ 10.1002/2014JC009831.

Connolly, T. P., and B. M. Hickey, 2014: Regional impact of submarine canyons during seasonal upwelling. J. Geophys. Res. Oceans, 119, 953-975, https://doi.org/10.1002/2013JC009452.

Cushman-Roisin, B., and J.-M. Beckers, 2011: Physical and Numerical Aspects. 2nd ed. Introduction to Geophysical Fluid Dynamics, Vol. 101, Academic Press, 875 pp.

Dawe, J. T., and S. E. Allen, 2010: Solution convergence of flow over steep topography in a numerical model of canyon upwelling. J. Geophys. Res., 115, C05008, https://doi.org/10.1029/ 2009JC005597.

Dinniman, M. S., and J. M. Klinck, 2002: The influence of open versus periodic alongshore boundaries on circulation near submarine canyons. J. Atmos. Oceanic Technol., 19, 17221737, https://doi.org/10.1175/1520-0426(2002)019<1722:TIOOVP> 2.0.CO;2.

— and - 2004: A model study of circulation and cross-shelf exchange on the west Antarctic Peninsula continental shelf. Deep-Sea Res. II, 51, 2003-2022, https://doi.org/10.1016/ j.dsr2.2004.07.030.

Durski, S. M., and J. Allen, 2005: Finite-amplitude evolution of instabilities associated with the coastal upwelling front. J. Phys. Oceanogr., 35, 1606-1628, https://doi.org/10.1175/JPO2762.1.

- — - G. Egbert, and R. Samelson, 2007: Scale evolution of finite-amplitude instabilities on a coastal upwelling front. J. Phys. Oceanogr., 37, 837-854, https://doi.org/10.1175/JPO2994.1.

Evans, W., B. Hales, P. G. Strutton, R. K. Shearman, and J. A. Barth, 2015: Failure to bloom: Intense upwelling results in negligible phytoplankton response and prolonged $\mathrm{CO}_{2}$ outgassing over the Oregon shelf. J. Geophys. Res. Oceans, 120, 1446-1461, https://doi.org/10.1002/2014JC010580.

Flament, P., L. Armi, and L. Washburn, 1985: The evolving structure of an upwelling filament. J. Geophys. Res., 90, 11 765-11 778, https://doi.org/10.1029/JC090iC06p11765.

Flather, R. A., 1976: A tidal model of the northwest European continental shelf. Mem. Soc. Roy. Sci. Liege, 6, 141-164.

Flexas, M., D. Boyer, M. Espino, J. Puigdefabregas, A. Rubio, and J. Company, 2008: Circulation over a submarine canyon in the NW Mediterranean. J. Geophys. Res., 113, C12002, https:// doi.org/10.1029/2006JC003998.

Florez-Leiva, L., E. Damm, and L. Farías, 2013: Methane production induced by dimethylsulfide in surface water of an upwelling ecosystem. Prog. Oceanogr., 112-113, 38-48, https:// doi.org/10.1016/j.pocean.2013.03.005.

Gan, J., and J. S. Allen, 2005: On open boundary conditions for a limited-area coastal model off Oregon. Part I: Response to idealized wind forcing. Ocean Modell., 8, 115-133, https:// doi.org/10.1016/j.ocemod.2003.12.006.

Grantham, B. A., F. Chan, K. J. Nielsen, D. S. Fox, J. A. Barth, A. Huyer, J. Lubchenco, and B. A. Menge, 2004: Upwellingdriven nearshore hypoxia signals ecosystem and oceanographic changes in the northeast Pacific. Nature, 429, 749-754, https://doi.org/10.1038/nature02605.

Haidvogel, D. B., H. G. Arango, K. Hedstrom, A. Beckmann, P. Malanotte-Rizzoli, and A. F. Shchepetkin, 2000: Model evaluation experiments in the North Atlantic Basin: Simulations in nonlinear terrain-following coordinates. Dyn. Atmos. Oceans, 32, 239-281, https://doi.org/10.1016/S0377-0265(00)00049-X.

Hernández-Miranda, E., R. Veas, F. A. Labra, M. Salamanca, and R. A. Quiñones, 2012: Response of the epibenthic macrofaunal community to a strong upwelling-driven hypoxic event in a shallow bay of the southern Humboldt Current
System. Mar. Environ. Res., 79, 16-28, https://doi.org/10.1016/ j.marenvres.2012.04.004.

Hickey, B., and N. Banas, 2008: Why is the northern end of the California Current System so productive? Oceanography, 21, 90-107, https://doi.org/10.5670/oceanog.2008.07.

Hickey, B. M., 1995: Coastal submarine canyons. Topographic Effects in the Ocean: Proc. 'Aha Huliko'a Hawaiian Winter Workshop, Honolulu, HI, University of Hawai'i at Mānoa, 95-110.

_ 1997: The response of a steep-sided, narrow canyon to timevariable wind forcing. J. Phys. Oceanogr., 27, 697-726, https:// doi.org/10.1175/1520-0485(1997)027<0697:TROASS > 2.0.CO;2. , 1998: Coastal oceanography of western North America from the tip of Baja California to Vancouver Island. The Global Coastal Ocean: Regional Studies and Syntheses, A. R. Robinson and K. H. Brink, Eds., The Sea-Ideas and Observations on Progress in the Study of the Seas, Vol. 11, John Wiley and Sons, 345-393.

Houghton, R., F. Aikman III, and H. Ou, 1988: Shelf-slope frontal structure and cross-shelf exchange at the New England shelfbreak. Cont. Shelf Res., 8, 687-710, https://doi.org/10.1016/ 0278-4343(88)90072-6.

Howatt, T., and S. Allen, 2013: Impact of the continental shelf slope on upwelling through submarine canyons. J. Geophys. Res. Oceans, 118, 5814-5828, https://doi.org/10.1002/jgrc.20401.

Huthnance, J. M., 1995: Circulation, exchange and water masses at the ocean margin: The role of physical processes at the shelf edge. Prog. Oceanogr., 35, 353-431, https://doi.org/10.1016/ 0079-6611(95)80003-C.

Huyer, A., 1983: Coastal upwelling in the California Current system. Prog. Oceanogr., 12, 259-284, https://doi.org/10.1016/ 0079-6611(83)90010-1.

Jordi, A., A. Orfila, G. Basterretxea, and J. Tintoré, 2005: Shelfslope exchanges by frontal variability in a steep submarine canyon. Prog. Oceanogr., 66, 120-141, https://doi.org/10.1016/ j.pocean.2004.07.009.

, G. Basterretxea, A. Orfila, and J. Tintoré, 2006: Analysis of the circulation and shelf-slope exchanges in the continental margin of the northwestern Mediterranean. Ocean Sci., 2, 173-181, https://doi.org/10.5194/os-2-173-2006.

_ J. M. Klinck, G. Basterretxea, A. Orfila, and J. Tintoré, 2008: Estimation of shelf-slope exchanges induced by frontal instability near submarine canyons. J. Geophys. Res., 113, C05016, https://doi.org/10.1029/2007JC004207.

Kämpf, J., 2006: Transient wind-driven upwelling in a submarine canyon: A process-oriented modeling study. J. Geophys. Res., 111, C11011, https://doi.org/10.1029/2006JC003497.

2007: On the magnitude of upwelling fluxes in shelf-break canyons. Cont. Shelf Res., 27, 2211-2223, https://doi.org/ 10.1016/j.csr.2007.05.010.

Kang, D., and E. N. Curchitser, 2015: Energetics of eddy-mean flow interactions in the Gulf Stream region. J. Phys. Oceanogr., 45, 1103-1120, https://doi.org/10.1175/JPO-D-14-0200.1.

Kim, S., R. Samelson, and C. Snyder, 2009: Ensemble-based estimates of the predictability of wind-driven coastal ocean flow over topography. Mon. Wea. Rev., 137, 2515-2537, https:// doi.org/10.1175/2009MWR2631.1.

Klinck, J. M., 1996: Circulation near submarine canyons: A modeling study. J. Geophys. Res., 101, 1211-1223, https://doi.org/ 10.1029/95JC02901.

Kock, A., S. Gebhardt, and H. W. Bange, 2008: Methane emissions from the upwelling area off Mauritania (NW Africa). Biogeosciences, 5, 1119-1125, https://doi.org/10.5194/bg-5-1119-2008. 
Kosro, P. M., J. A. Barth, and P. T. Strub, 1997: The coastal jet: Observations of surface currents over the Oregon continental shelf from HF radar. Oceanography, 10, 53-56, https://doi.org/ 10.5670/oceanog.1997.22.

Lachkar, Z., and N. Gruber, 2013: Response of biological production and air-sea $\mathrm{CO}_{2}$ fluxes to upwelling intensification in the California and Canary Current Systems. J. Mar. Syst., 109110, 149-160, https://doi.org/10.1016/j.jmarsys.2012.04.003.

Letelier, J., O. Pizarro, and S. Nuñez, 2009: Seasonal variability of coastal upwelling and the upwelling front off central Chile. J. Geophys. Res., 114, C12009, https://doi.org/10.1029/ 2008JC005171.

Liu, Y., X. San Liang, and R. H. Weisberg, 2007: Rectification of the bias in the wavelet power spectrum. J. Atmos. Oceanic Technol., 24, 2093-2102, https://doi.org/10.1175/ 2007JTECHO511.1.

Mellor, G. L., and T. Yamada, 1982: Development of a turbulence closure model for geophysical fluid problems. Rev. Geophys., 20, 851-875, https://doi.org/10.1029/RG020i004p00851.

Münchow, A., 2000: Wind stress curl forcing of the coastal ocean near Point Conception, California. J. Phys. Oceanogr., 30, 1265-1280, https://doi.org/10.1175/1520-0485(2000)030<1265: WSCFOT $>2.0 . \mathrm{CO} ; 2$.

Nelson, G., and L. Hutchings, 1983: The Benguela upwelling area. Prog. Oceanogr., 12, 333-356, https://doi.org/10.1016/00796611(83)90013-7.

O'Brien, J. J., and H. Hurlburt, 1972: A numerical model of coastal upwelling. J. Phys. Oceanogr., 2, 14-26, https://doi.org/10.1175/ 1520-0485(1972)002<0014:ANMOCU $>2.0 . C O ; 2$.

Orlanski, I., 1976: A simple boundary condition for unbounded hyperbolic flows. J. Comput. Sci., 21, 251-269, https://doi.org/ 10.1016/0021-9991(76)90023-1.

Ramos-Musalem, K., and S. E. Allen, 2019: The impact of locallyenhanced vertical diffusivity on the cross-shelf transport of tracers induced by a submarine canyon. J. Phys. Oceanogr., 49, 561-584, https://doi.org/10.1175/JPO-D-18-0174.1.

Rennie, S. J., C. B. Pattiaratchi, and R. D. McCauley, 2009: Numerical simulation of the circulation within the Perth Submarine Canyon, Western Australia. Cont. Shelf Res., 29, 2020-2036, https://doi.org/10.1016/j.csr.2009.04.010.

Samelson, R., and Coauthors, 2002: Wind stress forcing of the Oregon coastal ocean during the 1999 upwelling season. J. Geophys. Res., 107, 3034, https://doi.org/10.1029/2001JC000900.

Shchepetkin, A. F., and J. C. McWilliams, 2003: A method for computing horizontal pressure-gradient force in an oceanic model with a nonaligned vertical coordinate. J. Geophys. Res., 108, 3090, https://doi.org/10.1029/2001JC001047.

, and - 2005: The regional oceanic modeling system (ROMS): A split-explicit, free-surface, topography-followingcoordinate oceanic model. Ocean Modell., 9, 347-404, https:// doi.org/10.1016/j.ocemod.2004.08.002.
She, J., and J. M. Klinck, 2000: Flow near submarine canyons driven by constant winds. J. Geophys. Res., 105, 28 671-28 694, https://doi.org/10.1029/2000JC900126.

Skliris, N., A. Goffart, J. Hecq, and S. Djenidi, 2001: Shelf-slope exchanges associated with a steep submarine canyon off Calvi (Corsica, NW Mediterranean Sea): A modeling approach. J. Geophys. Res., 106, 19883-19 901, https://doi.org/10.1029/ 2000JC000534.

Sobarzo, M., G. S. Saldías, F. J. Tapia, L. Bravo, C. Moffat, and J. L. Largier, 2016: On subsurface cooling associated with the Biobio River Canyon (Chile). J. Geophys. Res. Oceans, 121, 4568-4584, https://doi.org/10.1002/2016JC011796.

Song, Y., and D. Haidvogel, 1994: A semi-implicit ocean circulation model using a generalized topography-following coordinate system. J. Comput. Phys., 115, 228-244, https://doi.org/ 10.1006/jcph.1994.1189.

Torrence, C., and G. P. Compo, 1998: A practical guide to wavelet analysis. Bull. Amer. Meteor. Soc., 79, 61-78, https://doi.org/ 10.1175/1520-0477(1998)079<0061:APGTWA > 2.0.CO;2.

Torres, R., and Coauthors, 2011: Air-sea $\mathrm{CO}_{2}$ fluxes along the coast of Chile: From $\mathrm{CO}_{2}$ outgassing in central northern upwelling waters to $\mathrm{CO}_{2}$ uptake in southern Patagonian fjords. J. Geophys. Res., 116, C09006, https://doi.org/10.1029/ 2010JC006344.

Troupin, C., E. Mason, J.-M. Beckers, and P. Sangrà, 2012: Generation of the Cape Ghir upwelling filament: A numerical study. Ocean Modell., 41, 1-15, https://doi.org/10.1016/ j.ocemod.2011.09.001.

Wang, D.-P., and A. Jordi, 2011: Surface frontogenesis and thermohaline intrusion in a shelfbreak front. Ocean Modell., $\mathbf{3 8}$ 161-170, https://doi.org/10.1016/j.ocemod.2011.02.012.

Washburn, L., and L. Armi, 1988: Observations of frontal instabilities on an upwelling filament. J. Phys. Oceanogr., 18, 1075-1092, https://doi.org/10.1175/1520-0485(1988)018<1075: OOFIOA $>2.0 . \mathrm{CO} ; 2$.

Whitney, M. M., and J. Allen, 2009a: Coastal wind-driven circulation in the vicinity of a bank. Part I: Modeling flow over idealized symmetric banks. J. Phys. Oceanogr., 39, 1273-1297, https://doi.org/10.1175/2008JPO3966.1.

_- and —_, 2009b: Coastal wind-driven circulation in the vicinity of a bank. Part II: Modeling flow over the Heceta Bank complex on the Oregon coast. J. Phys. Oceanogr., 39, 1298-1316, https://doi.org/10.1175/2008JPO3967.1.

Zhang, W. G., and G. G. Gawarkiewicz, 2015: Length scale of the finite-amplitude meanders of shelfbreak fronts. J. Phys. Oceanogr., 45, 2598-2620, https://doi.org/10.1175/JPO-D14-0249.1.

- and S. J. Lentz, 2017: Wind-driven circulation in a shelf valley. Part I: Mechanism of the asymmetrical response to along-shelf winds in opposite directions. J. Phys. Oceanogr., 47, 2927-2947, https://doi.org/10.1175/JPO-D-17-0083.1. 